\title{
Phase Change Materials as Smart Nanomaterials for Thermal Energy Storage in Buildings
}

\author{
M. Kheradmand ${ }^{1 \star}$, M. Abdollahzadeh ${ }^{2,3}$, M. Azenha ${ }^{4}$ and J.L.B. de Aguiar ${ }^{1}$ \\ ${ }^{1}$ Department of Civil Engineering, CTAC - Territory, Environment and \\ Construction Research Centre, University of Minho, School of Engineering, \\ Guimarães, Portugal \\ ${ }^{2}$ LEPABE - Laboratório de Engenharia de Processos, Ambiente e Energia, \\ Faculdade de Engenharia, Universidade do Porto, Porto, Portugal \\ ${ }^{3}$ Departamento de Engenharia Electromecanica, C-MAST - Center for \\ Mechanical and Aerospace Sciences and Technologies, \\ Universidade da Beira Interior, Covilha, Portugal \\ ${ }^{4}$ Department of Civil Engineering, ISISE - Institute for Sustainability and \\ Innovation in Structural Engineering, School of Engineering, \\ University of Minho, Guimarães, Portugal
}

\begin{abstract}
Nowadays, energy production and consumption in buildings play an important role in the economic development of countries. For instance, buildings are central to the EU's energy efficiency policy, as nearly $40 \%$ of final energy consumption and $36 \%$ of greenhouse gas emissions are attributable to houses, offices, shops, and other buildings. For achievement of highly energy-efficient buildings, significant paradigm shifts are necessary, particularly in the production requirements for cost-effective, durable, energy-efficient building envelopes. The application of phase change materials (PCMs) for thermal energy storage (TES) in building envelopes can assist the reduction of energy demands associated to the heating/ cooling necessary to ensure adequate inner thermal comfort. PCMs are defined as a group of materials that can store/release relevant quantities of thermal energy upon a change in their physical phase (latent heat). In many applications, such storage of energy leads to energy conservation within the system (i.e. the building), thus resulting in improved energy efficiency. Heat is absorbed or released when
\end{abstract}

${ }^{\star}$ Corresponding author: mohammadkheradmand@hotmail.com

Ashutosh Tiwari et al. (eds.) Intelligent Nanomaterials, Second Edition, (249-294) @ 2017

Scrivener Publishing LLC 
the material changes from solid to liquid and vice versa. Therefore, PCMs readily and predictably change their phase with a certain input of energy and release this energy at a later time. PCMs must have a suitable phase change temperature range and the latent heat of fusion for the building environment. The optimal phase change temperature depends on the comfort temperature. Also, a PCM must have an adequate conductivity rate to be able to react fast to indoor temperature variations. However, the phase change temperature ranges of the typical PCMs used in buildings are limited, and their thermal conductivity is low. To further improve the efficiency of the energy saving with PCM, the possibility of using more than one type of PCM with distinct melting ranges and specific enthalpies (termed as hybrid PCM) is reported here. Furthermore, a numerical study is conducted to investigate the mixture of nanoparticles and PCM as alternative way to enhance the thermal properties of PCM. On the basis of knowledge acquired here, concept of nanoparticle with PCM system can be employed to scopes of energy-efficient residential and commercial buildings.

Keywords: Buildings, phase change materials, nanoparticle, nanomaterials, construction materials

\subsection{Introduction}

Energy consumption in buildings and the corresponding costs are two major challenging concerns in most countries worldwide. In buildings, a large portion of energy consumption is used for heating and cooling. The challenge is to have the benefits from a construction with minimum energy demand for cooling/heating. In order to move towards sustainability in the buildings it is important to investigate methods that can reduce the cooling/heating energy demand.

One such method that can help in the reduction of peak heating/cooling loads and stabilization of indoor temperature is the use of phase change materials (PCMs) in a building construction to moderate thermal comfort. The addition of PCMs allows the building envelope to become an effective thermal energy storage (TES) system [1]. A well designed building envelope TES system can improve building operation by reducing the energy required to maintain the temperature ranges within comfort levels and shifting the time of the peak load on the electrical grid[2].

Several authors had studied PCM materials for building applications. PCM-based wallboards were studied by [3-5]. They concluded that wallboard based on PCM has excellent latent heat storage (LHS) capability and can shift energy consumption from peak load to an off-peak load period. In [6] it was reported that using a vacuum isolation panel (VIP) in a wallboard 
can reduce the thermal loss and improve efficiency for lightweight buildings. During summer, the efficiency of a PCM test cell was found to be remarkable with a reduction in temperature amplitude of $20^{\circ} \mathrm{C}$. In [7] PCM brick was constructed and experimentally studied for passive cooling. Experiments under free-floating conditions showed lower peak temperatures (up to $1{ }^{\circ} \mathrm{C}$ ) and more constant conditions in the cubicles with PCM, smoothing out the daily temperature fluctuations. Thermal performance of plastering mortar was assessed [8] with the purpose of enhancing the thermal comfort inside buildings. Their research presents the development and characterization of a new composite construction material that consists in embedding $25 \%$ microencapsulated PCM with melting point of $23{ }^{\circ} \mathrm{C}$, enthalpy of $100-110 \mathrm{~kJ} / \mathrm{kg}$ and $300 \mathrm{~kg} / \mathrm{m}^{3}$ density in plastering mortar.

Gómez et al. [9] studied an experimental research with precast self-compacting concrete panels containing $5 \%$ of PCM (melting point $23^{\circ} \mathrm{C}$, latent heat of $110 \mathrm{~kJ} / \mathrm{kg}$ and density of $980 \mathrm{~kg} / \mathrm{m}^{3}$ ). The main conclusion of their work was the achievement lower energy consumption during day time because PCM stores part of the energy received by cubicle. The research in [1] showed that enhancing thermal mass of concrete buildings seemed better than the use of PCM wallboards; however, the high cost of PCMs was the biggest concern. The research by Pasupathy [10] showed the effect of the building with PCM panel on the roof from the aspect of the location and thickness. He recommended a double layer of PCM to be incorporated in the roof to narrow indoor air temperature variation and to better suit the comfort demands for all seasons. An experimental investigation by Bentz et al. [11] showed the effect of incorporation of PCM on temperature variations within 2 days of hydration of cement mortars at semi-adiabatic conditions. They found that the use of PCM lowered the peak temperature by approximately $8{ }^{\circ} \mathrm{C}$ and delayed it by around $1 \mathrm{~h}$. Therefore, the heat evolution in mortar with PCM was strongly influenced by the presence of PCM.

The purpose of this chapter is to report the recent developments for further improving the TES system for increase energy efficiency in buildings. This intension was achieved on one hand by applying hybrid PCM systems for construction in plastering mortars of building façades and on the other hand by employing nanoparticle-enhanced PCMs for building heating and cooling systems. Such PCM system has the potential to control internal building temperatures with minimized energy consumption for both heating and cooling seasons.

This chapter initially is focused on the application of PCMs for TES in building envelopes. Experimental characterization of pure PCM materials and mortars at material level investigation are detailed to study the possibility of developing and employing hybrid PCM embedded mortars. Next, 
focus is given to small-scale tests of PCM-integrated building materials and then on the development and validation of a numerical simulation strategy for the thermal analysis of plaster mortar without PCM, with single PCM and with hybrid PCM-integrated into building envelopes. Afterwards, the applications of nanoparticle-enhanced phase materials for energy storage is demonstrated through numerical simulation using suitable models for nanoparticles and PCM.

\subsection{Phase Change Materials: Definition, Principle of Operation, and Classifications}

TES can be defined as the temporary storage of thermal energy at high or low temperatures. There are mainly two types of TES systems, sensible heat storage (SHS) and LHS, used for heat storage in the built environment [12]. In SHS, energy is stored or extracted by heating or cooling a liquid or solid. LHS is usually based on the heat absorption of a material when it changes phase from solid to liquid and on the heat release when it changes phase from liquid to solid. The principle of LHS is that, when ambient temperature rises, the chemical bonds of PCM will break up, and it will change phase from solid to liquid. This phase change is an endothermic process and it will absorb heat in regard to the heat capacity of the PCM. When the temperature drops again, the PCM will return to the solid state and it releases the heat [13]. In the solid-liquid phase change, storage of heat results in a change of phase and not in an increase in temperature. This storage in latent form has the advantage of greater heat storage capacity per unit volume compared to SHS.

The materials that take advantages of LHS are called PCMs [13]. By selecting PCM with a melting temperature close to the optimum indoor comfort temperature, the indoor temperature can stabilize and cut off peak cooling loads. In this way, a reduction in the cooling energy demand and improvement in thermal comfort can be achieved (Figure 9.1).

Two obvious requirements of a PCM to be used for building applications are suitable phase change temperature and a large melting enthalpy. They have to be fulfilled in order to store and release heat at all. However, there are more requirements for most, but not all applications. These requirements can be grouped into: thermal, physical, kinetic, chemical, and economical [14-16]. PCMs must have a suitable phase change temperature range for the building environment. The optimal phase change temperature depends on the comfort temperature desired by the building user and also by the climatic conditions [15]. Another important thermal 


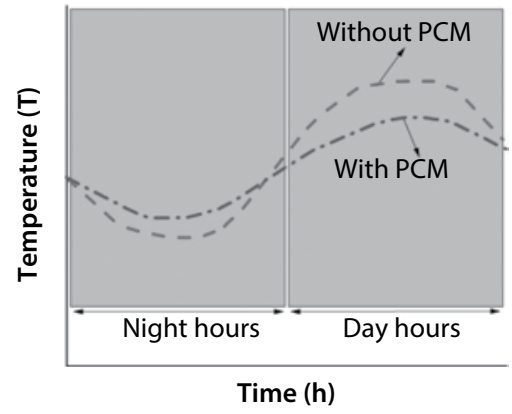

Figure 9.1 The function of PCM.

property of a PCM is the latent heat of fusion. The higher latent heat is the higher energy demand for the change of phase, and therefore the higher energy can be absorbed by the PCM. Also, a PCM must have an adequate conductivity rate to be able to react fast to indoor temperature variations. For example, when employed enormous masses of PCM inside a building with low thermal conductivity (not in a wall), they can fail to be activated because they do not meet temperature variations.

PCM for building applications requires long-term durability from the material in order to assure robust long-term performance. There must be a high chemical stability of the melting and solidification procedure and a completely reversible cycle. In the scope of building application, it is very important for a PCM to be compatible with construction materials.

PCMs can be classified in three different categories based on their chemical composition. The three different groups of PCMs are: (1) organic compounds, (2) inorganic compounds, and (3) eutectics [17]. Each different group has a typical range of melting temperature and melting enthalpy. Organic PCMs can be further divided into paraffins and fatty acids, and eutectics can be organic and inorganic combinations. The only type of inorganic PCMs is salt hydrates [16].

Organic PCMs are divided into two large groups: (1) paraffins and (2) non-paraffins. Paraffins have the advantage that they are available in a range of melting temperatures between 20 and $70{ }^{\circ} \mathrm{C}$ and therefore can be used for indoor temperature stabilization [16]. Another advantage is that they are chemically inert, and they can be easily implemented in building construction [17]. Also, their thermal performance is not affected by the number of cycles [18]. Their thermal storage capacity is between 100 and $210 \mathrm{~kJ} / \mathrm{kg}$. Also, paraffins have a thermal conductivity about $0.2 \mathrm{~W} /(\mathrm{m} \mathrm{K})$ [1]. Flammability of organic PCMs is a problem that has been hindering their wider implementation for the last 20 years. However, Kosny et al. [19] 
developed an encapsulation of cellulose and fiberglass that improved the fire resistivity. The non-paraffin organics include a wide selection of organic materials such as fatty acids, esters, alcohols and glycols [14]. They have certain advantages compared to paraffins, such as higher latent heat of fusion and a smaller volume change during their phase transition which could make them a comparably preferable material [20]. However, there is a lack of materials with a melting point near $21^{\circ} \mathrm{C}$, which is ideal for indoor comfort. Their melting points are between 16 and $65^{\circ} \mathrm{C}$ and freezing points between $17^{\circ} \mathrm{C}$ and $64^{\circ} \mathrm{C}$, with a heat of fusion between 155 and $180 \mathrm{~kJ} / \mathrm{kg}$. Also, their price is almost three times higher than the price of paraffins [1].

In comparison with organic PCMs, inorganic PCMs have better thermal properties because they have a high latent heat of fusion between 180 and $440 \mathrm{~kJ} / \mathrm{kg}$ approximately. Also, they have a higher thermal conductivity (about $0.5 \mathrm{~W} / \mathrm{mK}$ ) when compared with paraffins. Another important advantage for their implementation in the built environment is their low price and also the fact that they are non-flammable [18]. The main disadvantage of inorganic PCMs is the phase segregation that they show after a relatively short number of cycles (1000 melt/freeze cycles) [17]. This happens because hydrated salts melt congruently with formation of lower salts, making the process irreversible after a number of cycles, resulting in reduction of their heat storage capacity and their robustness [21].

Eutectics, or eutectic mixtures, are mixtures of multiple solids in certain proportion in order to have the lowest melting point possible. They have a sharp melting point (small melting-solidification temperature range) which enables them to be used to maintain a specific indoor temperature and their volumetric storage density is slightly higher than that of organic compounds. Eutectics are divided into three categories: (1) organicorganic, (2) inorganic-inorganic, and (3) inorganic-organic [18].

\subsection{PCM-enhanced Cement-based Materials}

Usually, cement-based materials such as: concrete and mortar are widely used as construction materials [22]. Due to the fact that, they have large thermal mass this can be advantageous, especially in moderate climates where they can be used to store energy during the day and release it during night time therefore reducing the need for auxiliary cooling and heating [23]. Moreover, the energy storage capacity of concrete or mortar can further be enhanced by the incorporation of PCM into the mixtures. Plastering PCM-enhanced mortar combines an appropriate PCM with a 
mortar matrix producing mortar with enhanced thermophysical properties [8]. Cement-based materials are considered suitable for incorporation of PCM because of the following reasons [24, 25]: (1) they are the most widely used construction materials, (2) they can be formed into a variety of shapes and sizes, (3) they have a larger heat exchange area and smaller heat exchange depth, (4) production and quality control can be easily achieved, and (5) ease of testing.

Integration of PCM in cement-based materials is accomplished through several strategies. The incorporation of PCM can be as part of separate building components, or as additive to ordinary building materials. The main methods that have been used are immersion, direct incorporation, encapsulation (micro and macro) [16], and shape-stabilized PCMs [26].

\subsection{Hybrid PCM for Thermal Storage}

The melting range and enthalpy of the PCM influence the efficiency of the energy saving in the building. The possibility of using more than one type of PCM with distinct melting ranges and specific enthalpies (termed as hybrid PCM) in the same plastering mortar for improvement of the effectiveness of the PCM-based system is studied in our previous work [27]. Such possibility was solely assessed at the material level in what concerns to homogeneity distribution at different matrices within plastering mortar and the behavior of hybrid PCMs under differential scanning calorimetry (DSC) testing. Three types of encapsulated organic PCM paraffins were considered (Devan Mikrathermic D series): MC18 (melting temperature of $18{ }^{\circ} \mathrm{C}$ ), MC24 (melting temperature of $24^{\circ} \mathrm{C}$ ), and MC28 (melting temperature of $28^{\circ} \mathrm{C}$ ). The technical specifications of the PCMs [28] report a mean size of the encapsulated spherical paraffin particles of around $18 \mu \mathrm{m}$ for MC18, MC24, and MC28 (see Table 9.1). Scanning electron microscope (SEM) imaging of these materials revealed a large variation of the particle size around the average value, as seen in Figure 9.2a. In fact, the smallest paraffin particles were around $3 \mu \mathrm{m}$ in diameter and the largest reached

Table 9.1 Properties of PCMs provided by supplier [28].

\begin{tabular}{|l|c|c|}
\hline Properties & Melting point $\left({ }^{\circ} \mathbf{C}\right)$ & Latent heat of fusion $(\mathbf{J} / \mathbf{g})$ \\
\hline MC18 & 18 & 180.40 \\
\hline MC24 & 24 & 147.90 \\
\hline MC28 & 28 & 170.10 \\
\hline
\end{tabular}




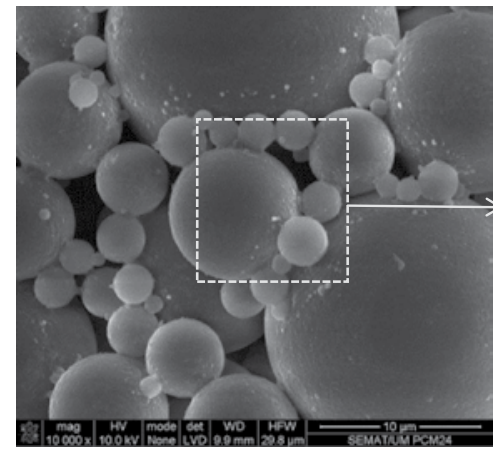

(a)

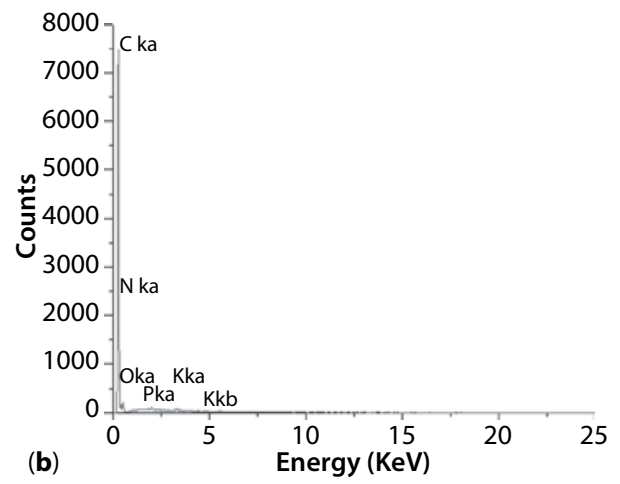

Figure 9.2 (a) Particle size characteristics of microencapsulated PCM powder (MC24); (b) EDS spectrum of the PCM (MC24).

approximately $26 \mu \mathrm{m}$. With these three types of PCMs, four samples were prepared for DSC tests: three samples that solely contained one type of PCM (MC18, MC24, or MC28) and one sample that contained a 50-50\% mass proportion mix of MC18 and MC28, here termed as MC18_28. The tested samples had average weight of $\sim 4 \mathrm{mg}$. The morphology of bulk PCM can be observed in Figure 9.2a, where only PCM particles can be seen without any extra substances. It should be noted that the energy-dispersive $\mathrm{X}$-ray spectroscopy (EDS)/SEM analysis of the pure microencapsulated PCMs has a strong peak appeared in the elemental analysis of the PCM is the carbon element $(\mathrm{C})$ which is the main component of the PCM material (see Figure 9.2b).

The results of the DSC experiments for the pure PCMs are detailed in the following sections and presented in Table 9.2. None of the tested PCMs revealed melting temperatures (peak points) coinciding with the reference value indicated by the supplier, with maximum deviations reaching $3.74 \mathrm{~K}$. Furthermore, the difference between the melting peak temperature and the freezing peak temperature was of $3.29,4.5$, and $2.42 \mathrm{~K}$ for MC18, MC24, and MC28, respectively. For the sample of MC18_28, the difference between the melting peak temperatures and the freezing peak temperatures was of 2.7 and $1.86 \mathrm{~K}$ for the phase changes corresponding to $\mathrm{MC} 18$ and MC28, respectively.

In the MC18_28 sample, the phase change melting temperatures were coherent with those of the components of the mix (MC18 and MC28). This indicates that, the mixing of two PCMs had similar behavior to the independent PCMs and it can be inferred that they have not endured unexpected interactions with each other [27]. For illustrative purposes, Figure 9.3a shows the DSC heating curves of MC18 and MC28 separately 
Phase Change Materials as Smart Nanomaterials 257

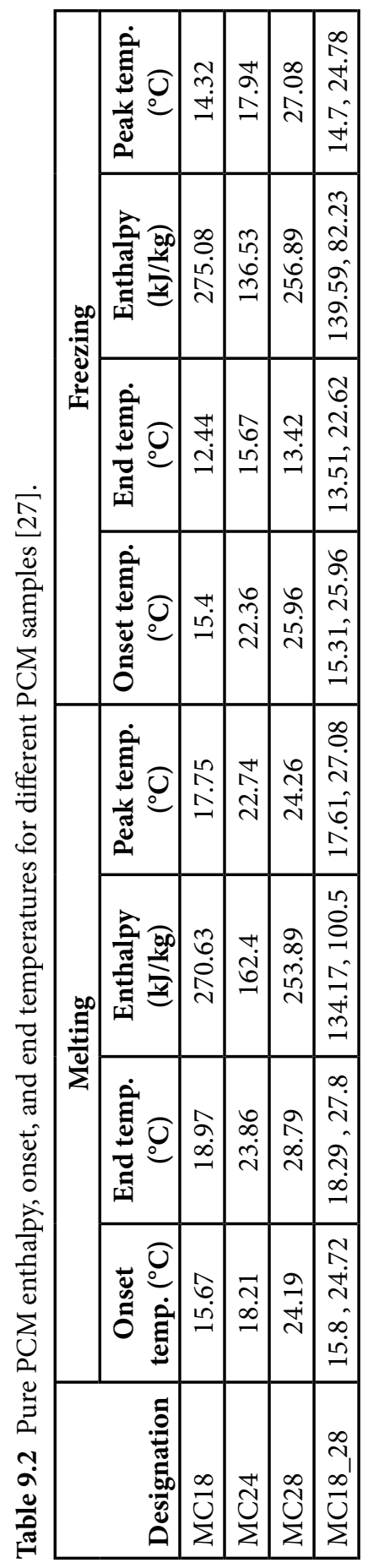


and also, superimposed graphically to the result of MC18_28 sample. It can be observed that, the specific enthalpy value of MC18_28 at $\sim 18{ }^{\circ} \mathrm{C}$ is almost half of the specific enthalpy of the MC18 sample at the same transition temperature. This is coherent with the fact that MC18_28 has half of the quantity of $18{ }^{\circ} \mathrm{C}$ PCM when compared with MC18. A similar tendency is observed for the $28{ }^{\circ} \mathrm{C}$ transition (however, with slightly higher deviation). Figure 9.3b shows the results obtained by DSC have the same thermal behavior during the heating process: highest peak at $24^{\circ} \mathrm{C}$ in a melting temperature range between $\approx 18{ }^{\circ} \mathrm{C}$ and $\approx 24^{\circ} \mathrm{C}$. The melting enthalpy of MC24 sample analyzed has a value $162.4 \mathrm{~kJ} / \mathrm{kg}$ [27].

In our recent work [27], a material level investigation was conducted with a reference plain mortar (mortar REFM) and two mortar systems which incorporate respectively a single type of PCM with $24^{\circ} \mathrm{C}$ of melting temperature (mortar SPCMM24), or the combination of two PCMs with melting temperatures of 18 and $28^{\circ} \mathrm{C}$ (mortar HPCMM18_28).

These plastering mortars and their adopted designations are listed in Table 9.3. Mortar SPCMM24 contains $18.34 \%$ in weight of MC24, whereas HPCMM18_28 has the same total percentage of PCM, evenly distributed among MC18 and MC28. The formulation of the mortars was selected based on recent developments that allowed nearly $20 \%$ mass fractions of PCM to be incorporated in mortar, while maintaining satisfactory performance in terms of mechanical properties/behavior [29, 30]. In fact, the adopted formulations for mortar with and without PCM was successfully encompassed the problem related with the mortar shrinkage and consequent cracking, by adding superplasticizer into the mixture [30].

Regarding specimen preparation in the scope of SEM/EDS analysis, a total number of 12 specimens were used. This includes four representative specimens of each mortar system for the SEM/EDS investigation focused on the assessment of the spatial homogeneity of the mortar. All test samples were obtained from mortar casted in cylindrical moulds with
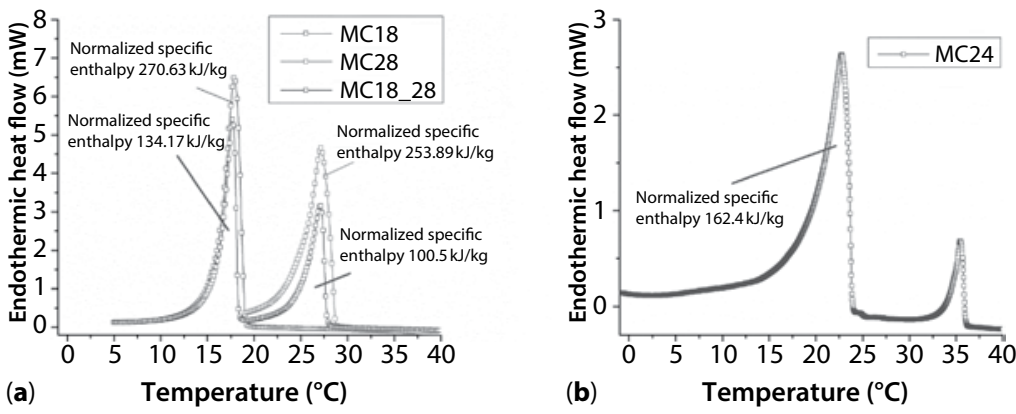

Figure 9.3 Heating DSC curves for: (a) MC18, MC28, and MC18_28; and (b) MC24. 
Table 9.3 Mix proportions of formulations SPCMM24, HPCMM18_28 and REFM [27].

\begin{tabular}{|l|c|c|c|}
\hline \multirow{2}{*}{ Materials } & \multicolumn{3}{|c|}{ Formulations $\begin{array}{c}\text { (percentage of the total weight of } \\
\text { mortar) }\end{array}$} \\
\cline { 2 - 4 } & REFM & SPCMM24 & HPCMM18_28 \\
\hline Cement type I -42.5R & 22.64 & 31.32 & 31.32 \\
\hline Sand & 64.23 & 30.59 & 30.59 \\
\hline Water & 12.45 & 18.79 & 18.79 \\
\hline Super plasticizer & 0.63 & 0.94 & 0.94 \\
\hline MC18 & - & - & 9.18 \\
\hline MC24 & - & 18.34 & - \\
\hline MC28 & - & - & 9.18 \\
\hline
\end{tabular}

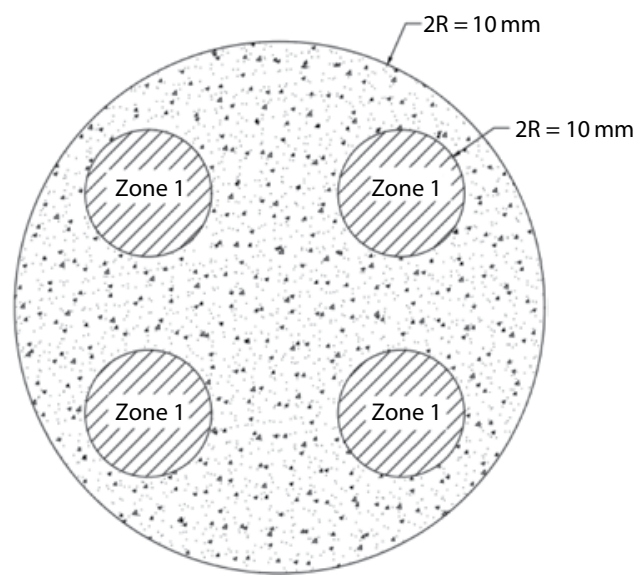

Figure 9.4 Generic view of the sample with identification of the zone for surface study of the plastering mortars (Zones 1-4).

diameter of $100 \mathrm{~mm}$, which were cured for 28 days, before the process of sampling (Figure 9.4).

The detailed classification of the type of specimen, selected test method as well as the location of the region of interest for the SEM/EDS studies of the mortars are presented in Table 9.4.

The results here reported deal with determination of elements of investigated surface of the mortar containing one or more types of 
Table 9.4 Required test method and region with respect to the materials identification.

\begin{tabular}{|l|l|c|c|}
\hline Names & Material & Region & Test method \\
\hline REFMZ1 & Conventional mortar & Zone 1 & SEM/EDS test \\
\hline REFMZ2 & Conventional mortar & Zone 2 & SEM/EDS test \\
\hline REFMZ3 & Conventional mortar & Zone 3 & SEM/EDS test \\
\hline REFMZ4 & Conventional mortar & Zone 4 & SEM/EDS test \\
\hline SPCMZ1 & Mortar contains MC24 & Zone 1 & SEM/EDS test \\
\hline SPCMZ2 & Mortar contains MC24 & Zone 2 & SEM/EDS test \\
\hline SPCMZ3 & Mortar contains MC24 & Zone 3 & SEM/EDS test \\
\hline SPCMZ4 & Mortar contains MC24 & Zone 4 & SEM/EDS test \\
\hline HPCMZ1 & Mortar contains MC18 and MC28 & Zone 1 & SEM/EDS test \\
\hline HPCMZ2 & Mortar contains MC18 and MC28 & Zone 2 & SEM/EDS test \\
\hline HPCMZ3 & Mortar contains MC18 and MC28 & Zone 3 & SEM/EDS test \\
\hline HPCMZ4 & Mortar contains MC18 and MC28 & Zone 4 & SEM/EDS test \\
\hline
\end{tabular}

microencapsulated PCM or without microencapsulated PCM. REFM, SPCMM24, and HPCMM18_28 specimens after being polished according to the method mentioned before, each sample was conducted to an energy dispersive X-ray spectrometer (EDS) attached to the SEM for elemental analysis.

The general view of the microstructure of the investigated mortars is presented in Figure 9.5. In a reference plain mortar and PCM enriched mortar, the sand particles tend to be distributed uniformly on the surface of the investigated material (see, for example, REFM, Figure 9.5a). No signs of agglomeration were observed, suggesting spatially homogeneous microstructures in both cases. The aggregate inclusions of quartz are hosted by the cementitious matrix composed predominantly of calcium-silicahydrates $(\mathrm{C}-\mathrm{S}-\mathrm{H})$ and portlandite $(\mathrm{CH})$ [31]. The microencapsulated paraffin wax particles are incorporated in the microstructure of SPCMM24 mortar (Figure 9.5b). It is observed, despite the different nature of the PCM particles (organic) and cement hydration products (inorganic), their microstructural assembly tends to be sound and continuous, with hydration products tightly encompassing the PCM external boundary. SEM 


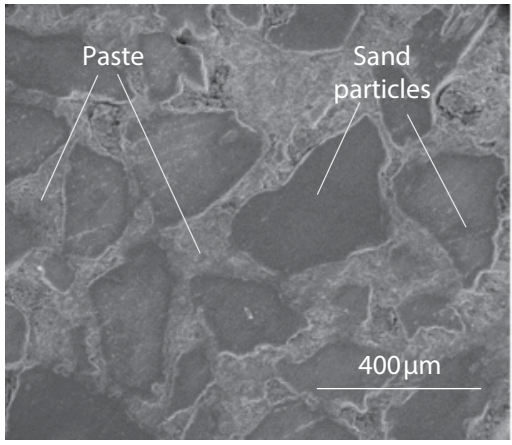

(a)

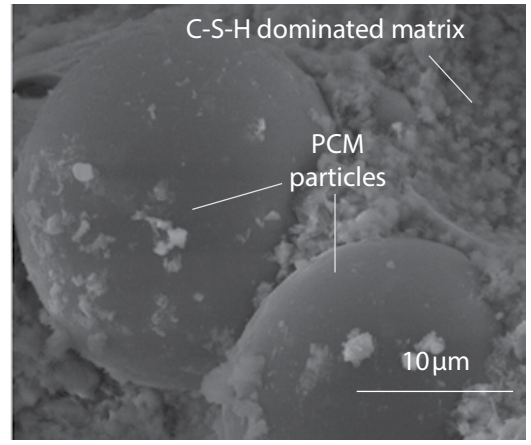

(b)

Figure 9.5 SEM images of surface of the specimens: (a) SEM micrograph of the reference specimen with formulation of REFM; (b) SEM micrograph of the plastering mortar sample with formulation of SPCMM24 [32].

results tend to suggest adequate compatibility and spatial homogeneity of the PCM materials, which is important factor in the selection, analysis and understanding of the microstructure of the mortars [32].

The energy spectrum of different zones for different mortar specimens as well as for the pure PCM sample (MC24) was performed. Figure 9.6 presents the counts versus energy as well as zoomed region of interests for surface analyses. As it can be seen in Figure 9.6a, the carbon $C$ element is identifiable with slight peaks for all studied zones of REFM samples. It can be concluded that, the REFM specimen have no sign of carbon C element. From the EDS result of SPCMM24 and HPCMM18_28 specimens, the most abundant elements are $\mathrm{O}, \mathrm{C}$, and $\mathrm{N}$ in the interested region (see Figure $9.6 \mathrm{~b}$ and c). Bear in mind, the pure PCM that has a strong peak of $\mathrm{C}$ element; it was expected to appear such a peak in the mortars with PCM. It is obvious that a strong peak of carbon $\mathrm{C}$ element and consequently the spectrum of both samples, SPCMM24 and HPCMM18_28 have higher intensity of carbon $\mathrm{C}$ element peaks when compared with REFM. These increased behaviors were expected as carbon $\mathrm{C}$ element is the principal elements for the PCM's material. However, these intensities of the carbon C element for different zones of PCM mortar samples appeared with slightly differences (see Figure 9.6). This simple criterion has been used to establish the homogeneity of the sample for the elements of interest [33]. The results of these analysis showed that, the PCMs in both, single PCM and hybrid PCM mortars appeared on the surfaces of SPCMM24 and HPCMM18_28 samples.

The energy saving potential of hybrid PCMs was analyzed in our previous work [34]. Small-scale prototypes under realistic daily temperature 

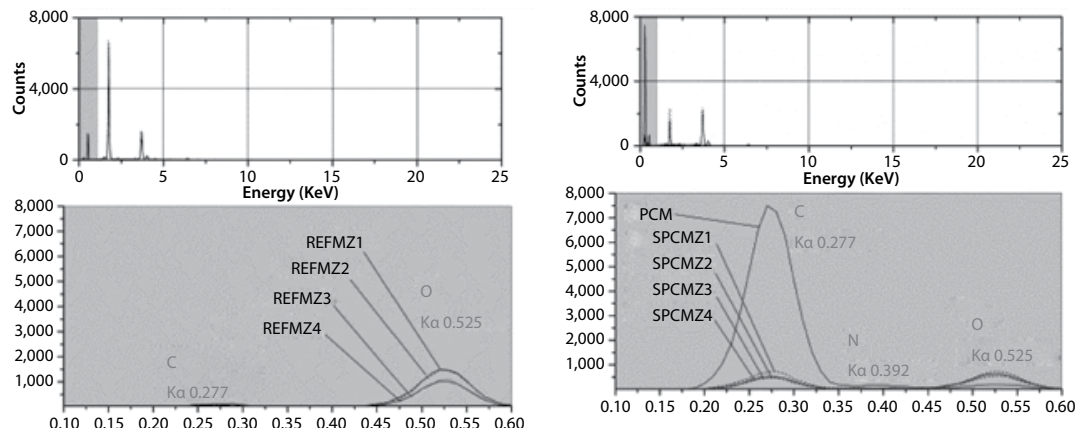

(a)

(b)
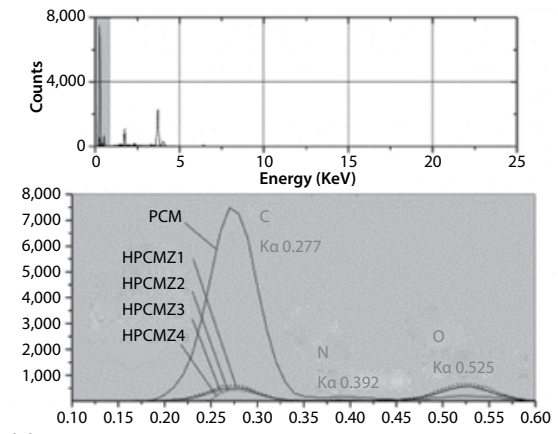

(c)

Figure 9.6 The surface analysis SEM/EDS for different zones of each formulation: (a) REFM, (b) SPCMM24, and (c) HPCMM18_28.

histories were studied. The hybrid PCM was incorporated into plastering mortar coated as a render on the extruded polystyrene (XPS) surfaces (prototypes shaped as a hollow cubes). The closed cubes were placed into a climatic chamber and subjected to simulated real temperature variations, thus allowing evaluation of the differences in thermal performance of the two types of tested mortars.

Regarding hybrid PCM mortar, four types of organic PCMs were considered: RT10 with melting temperature of $10{ }^{\circ} \mathrm{C}$ [from Rubitherm paraffin RT series [35]], MC28 with melting temperature of $28{ }^{\circ} \mathrm{C}, \mathrm{MC} 24$ with melting temperature of $24^{\circ} \mathrm{C}$ [from DEVAN microencapsulated MC series [28]], and BSF26 with melting temperature of $26^{\circ} \mathrm{C}$ [from BASF microencapsulated Micronal series [36]] were selected. The properties of the selected PCMs for this study, as provided by their manufacturers, are presented in Table 9.5. The mix designs of the two mortars studied herein, together with their adopted designations (REFM for the reference mortar and HPCMM for the hybrid PCM mortar) are presented in Table 9.6. 
Table 9.5 Properties of PCMs, provided by suppliers.

\begin{tabular}{|l|c|c|c|c|}
\hline Properties & $\begin{array}{c}\text { Operating } \\
\text { temperature } \\
\text { ranges }\left({ }^{\circ} \mathbf{C}\right)\end{array}$ & $\begin{array}{c}\text { Latent heat of } \\
\text { fusion }(\mathbf{J} / \mathbf{k g})\end{array}$ & $\begin{array}{c}\text { Apparent } \\
\text { Melting } \\
\text { point }\left({ }^{\circ} \mathbf{C}\right)\end{array}$ & $\begin{array}{c}\text { density at solid } \\
\text { stage }\left(\mathbf{k g} / \mathbf{m}^{3}\right)\end{array}$ \\
\hline RT10 & $2-12$ & 150,000 & 10 & 880 \\
\hline MC24 & $12-25$ & 162,400 & 24 & $*$ \\
\hline BSF26 & $10-30$ & 110,000 & 26 & 350 \\
\hline MC28 & $22-32$ & 170,100 & 28 & $*$ \\
\hline
\end{tabular}

* No information available on behalf of the suppliers.

Table 9.6 Mix proportions of formulations REFM and HPCMM [34].

\begin{tabular}{|c|c|c|}
\hline \multirow[b]{2}{*}{ Materials } & \multicolumn{2}{|c|}{$\begin{array}{c}\text { Formulations (percentage of the total weight of } \\
\text { mortar) }\end{array}$} \\
\hline & REFM & НРСММ \\
\hline Cement type I-42.5R & 22.64 & 31.32 \\
\hline Sand & 64.23 & 30.59 \\
\hline Water & 12.45 & 18.79 \\
\hline Super plasticizer & 0.63 & 0.94 \\
\hline RT10 & - & 6.12 \\
\hline BSF26 & - & 6.12 \\
\hline MC28 & - & 6.12 \\
\hline
\end{tabular}

In order to assess the effect of the hybrid PCM concept into plastering mortars used as internal coatings for buildings, two closed prototypes were built with laboratory-scale dimensions. The materials used for the construction of the prototypes were from inside to outside: a $0.02-\mathrm{m}$-thick layer of REFM or HPCMM, and a 0.03 m thick of XPS. Each prototype was placed inside a controlled climatic chamber with inner dimensions of $1.04 \mathrm{~m} \times 1.2 \mathrm{~m} \times 0.6 \mathrm{~m}$. The temperature cycles through the exterior surfaces of the model were programmed to match the sol-air temperature corresponding to the surface temperature of a vertical wall facing south, which is considered for summer and winter time in Portugal. The physical arrangement of this setup can be observed at the pictures of the prototype and monitoring system showed in Figure 9.7. 


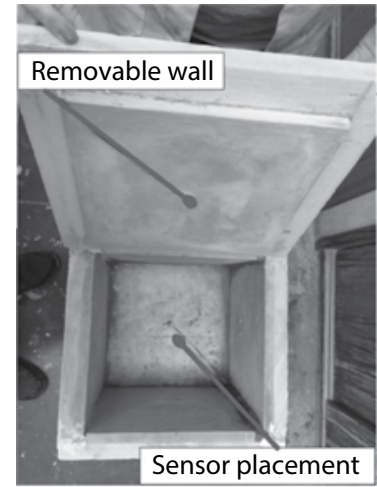

(a)

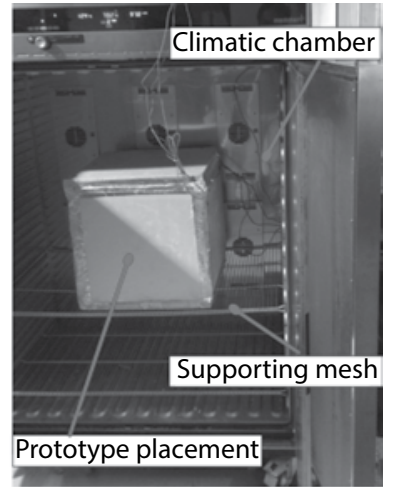

(b)

Figure 9.7 (a) Picture of sensor arrangement at geometrical centre inside prototype; (b) Picture of the test setup configuration [34].

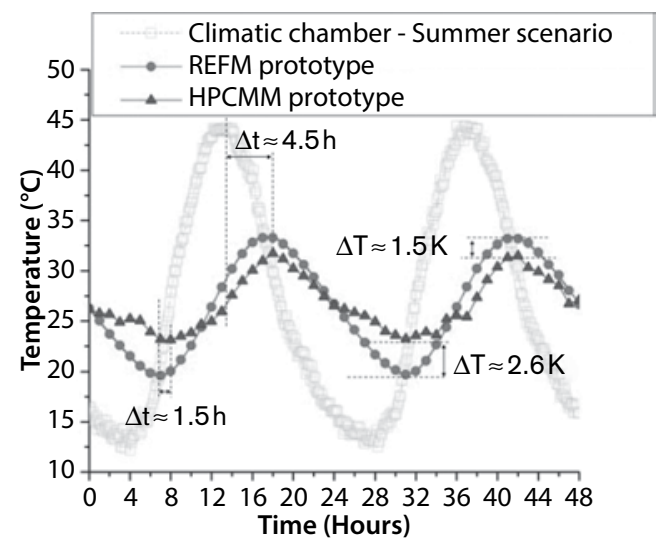

Figure 9.8 Monitored temperatures of the prototypes with inner coatings made of HPCMM and REFM under summer scenario [34].

The monitored results registered for both prototypes under summer day conditions for instance, shown in Figure 9.8. In this figure, the minimum peak temperature differences of $2.6 \mathrm{~K}$ are reasonably consistent with the observations of [8], who observed similar magnitude peak temperature differences of $2-3 \mathrm{~K}$ in prototypes containing mortar with a single PCM and without PCM (mentioned earlier). However, the maximum internal temperatures inside the prototypes are also different $(1.5 \mathrm{~K}$ difference between REFM and HPCMM), confirming HPCMM can also help to moderate temperature in this range. Furthermore, the delay between the maximum temperatures registered inside climatic chamber and inside the 
HPCMM prototype was of nearly $4.5 \mathrm{~h}$. Also, the difference in such delay between the REFM and HPCMM prototypes was of approximately $1.5 \mathrm{~h}$, with advantage for HPCMM [34]. The given example of summer scenario testing, revealed that hybrid PCM acts by reducing inside temperature amplitudes during the day, leveling them, and turning them closer to comfort temperature levels (around $24^{\circ} \mathrm{C}$ ).

It should be mentioned that in this work we have also tested the same mortar under winter scenario. However, it was observed that neither REFM nor HPCMM prototypes meet the thermal comfort level. This situation would not be acceptable in a real case-scenario, where a heating element would be added to the system. Due to this fact, we decided to use such heating element in the prototype; the increased capacity of HPCMM in attenuating thermal amplitudes as compared to REFM was demonstrated as intended. Therefore, further research works were specifically focussed on integrating a heating element within the studied prototype and evaluating energy savings associated to the inclusion of hybrid PCM mortars. The target is to assess the energy efficiency gains for space heating using hybrid PCMs into plastering mortars used as internal coatings for buildings. The heating system was placed inside the box (centre of the heater coinciding with the geometrical centre of the cube). The heater had dimensions of $0.02 \mathrm{~m} \times 0.02 \mathrm{~m} \times 0.1 \mathrm{~m}$, with a power rating of $300 \mathrm{~W}$. The heater was connected to a multifunctional electricity source with alternative parameters (Ampere and Voltage for the output) and a temperature controller in order to control internal temperature sets of the ambient temperature of the prototype. The control of the heating system was made in order to maintain a temperature of comfort level. The standard [37] recommends that air temperature inside the building should be between minimum $21{ }^{\circ} \mathrm{C}$ and maximum $25^{\circ} \mathrm{C}$ during winter season. The heater is $\mathrm{ON}$ when the temperature inside the box goes below the $21^{\circ} \mathrm{C}$, and it is turned OFF when the temperature reaches $21{ }^{\circ} \mathrm{C}$ again. On the other hands, the control mode used was dependent on the interior temperature of the prototype. If it is smaller than $21^{\circ} \mathrm{C}$, the controller proceeds to "ON mode" and interior air temperature of the prototypes is kept within the "low peak temperature" range of 21 and $25^{\circ} \mathrm{C}$. The physical arrangement of this setup can be observed at the pictures of the prototype/monitoring shown in Figure 9.9.

Figure 9.10a shows the air temperature variations of the REFM prototype over a 24 -h period with respect to the heater element. As shown in this figure, during a cycle of $24 \mathrm{~h}$, interior air temperature was kept at the minimum comfort temperature of about $20^{\circ} \mathrm{C}$ according to the predefined set point temperature for the heater. During first 9-h period, when the 


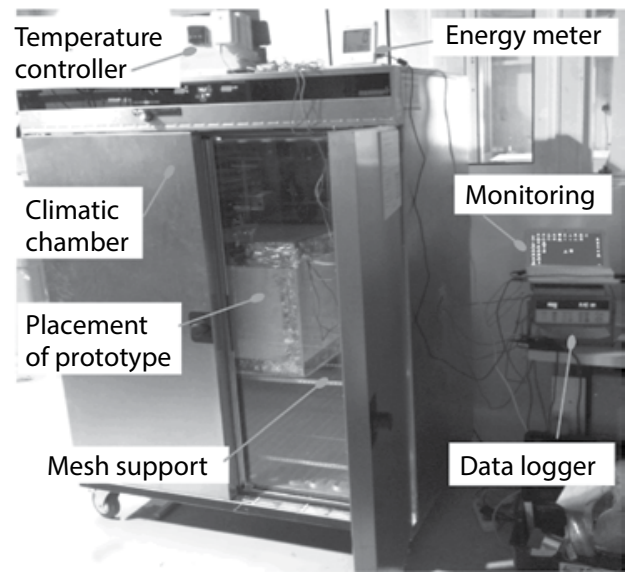

Figure 9.9 Photo of the prototype ready for testing, highlighting the location of the prototype within the climatic chamber.

ambient temperature drops to below $14{ }^{\circ} \mathrm{C}$, the interior temperature of the prototype reaches to the limit temperature of $20^{\circ} \mathrm{C}$. At this time, the heater system stops to work as the ambient temperature rises above the set point of $20^{\circ} \mathrm{C}$. At the time of $\mathrm{t} \approx 9$ to $17 \mathrm{~h}$, the heater system was in the "OFF mode" and therefore, the monitored interior temperature within the prototype getting narrows to it is set point temperature of $20^{\circ} \mathrm{C}$ again. On the other hand, at the both times of $\mathrm{t} \approx 17$ and $24 \mathrm{~h}$, the interior air temperature reached $20^{\circ} \mathrm{C}$ and the temperature controller turned on the heater element in order to prevent further temperature drop in the prototype.

The results of thermal behavior in the hybrid PCM prototype (HPCMM) are shown in Figure 9.10b. In fact, Figure 9.10b is homologous to Figure 9.10a, except for the fact that it deals with HPCMM. The observations are also analogous to those already made for REFM. In brief, in the case of HPCMM, there is a possibility of taking advantages of PCMs due to the fact that they can absorb or release the heat during their phase change temperatures. The air temperature for HPCMM remains above the temperature constraint until the prototype is heated as a result of heating element as well as phase change transition of PCM within mortar. This shows clearly that the PCM can successfully be used for $\mathrm{t} \approx 0-10 \mathrm{~h}$ and $19-24 \mathrm{~h}$.

Comparing Figure 9.10a and b, the good performance of the HPCMM in compare with REFM in the early hours of cycle highlighted. This allows $1 \mathrm{~h}$ delaying in the time to reach to the $20^{\circ} \mathrm{C}$ as the temperature drops in REFM by $\mathrm{t} \approx 0-9 \mathrm{~h}$ and in HPCMM by $\mathrm{t} \approx 0-10 \mathrm{~h}$. This is 

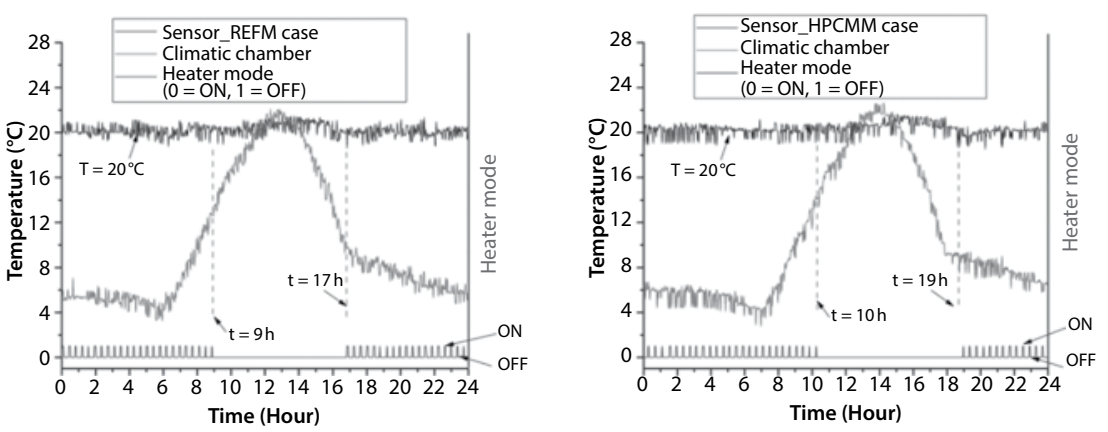

Figure 9.10 Monitoring temperature variations at different positions inside the prototypes under tested controlled environment accounting heater modes: (a) REFM and (b) HPCMM.

because there is usually no need for heating during the first $10 \mathrm{~h}$ and, as a consequence, the stored energy in the HPCMM is discharged. This can be clearly observed in Figure 9.10b, which shows that the HPCMM case was turned on the heater and, suggesting that the PCM is discharged and can contribute to the heating of the HPCMM prototype. For further evaluating the impact of the PCM on thermal efficiency of the system, the accumulative energy consumption by the heater equivalent to the both cases of REFM and HPCMM were calculated for a period of 24 h. The configuration with PCM allowed approximately $20 \%$ reduction in energy demands for maintaining the temperature inside the prototypes within the comfort temperature. This shows that the electricity saving achieved in each day comes from PCMs and is affected by outdoor temperature.

\subsection{Numerical Simulations}

This section deals with introducing available thermal models as well as phase change models in the context of building physic. Furthermore, several case studies were performed in order to indicate the potential advantages of the simulation from small-scale to real-scale dimensions.

\subsubsection{Numerical Simulation of Heat Transfers in the Context of Building Physics}

Computational fluid dynamics (CFD) is used for modeling temperature variations inside the building and the PCMs. The CFD models have been 
used widely to study indoor air quality and thermal comfort in buildings $[9,38,39]$. One of the difficulties in the modeling is to reproduce the PCM effect according to the frame of the problem. Such effort requires advanced simulation techniques that involve complex thermal exchange phenomena, leading many of currently existing simplified simulation approaches to provide results that deviate from experimental evidences [18]. This is important from the aspect of building physic modeling.

\subsubsection{Governing Equations}

In order to simulate the energy storage/saving potential of the PCM embedded walls, the air flow and temperature fields in indoor environments, temperature fields inside the walls and the PCM need to be modeled. The heat transfer mechanism in the air is governed by natural convection and conduction heat transfer. Assuming that all the involved materials are homogeneous and isotropic, governing equations of the considered problem can be summarized as follows [63]:

Continuity:

$$
\frac{\partial\left(\rho_{\text {eff }}\right)}{\partial t}+\nabla \cdot\left(\rho_{\text {eff }} \vec{v}\right)=0
$$

Momentum equation:

$$
\frac{\partial\left[\rho_{\text {eff }} \vec{v}\right]}{\partial t}+\nabla \cdot\left(\rho_{\text {eff }} \vec{v} \vec{v}\right)=-\nabla p+\nabla \cdot(\bar{\tau})+\rho_{\text {eff }} \bar{g}+S_{u}
$$

Energy equation

$$
\frac{\partial\left[\rho_{\text {eff }} H\right]}{\partial t}+\nabla \cdot\left(\rho_{\text {eff }} \vec{v} H\right)=\nabla \cdot\left(\frac{k_{\text {eff }}}{c_{p, e f f}} \nabla H\right)+S_{h}
$$

The density of the air is calculated based on the ideal gas law as follows:

$$
\rho_{\text {Air }}=\frac{P}{R T}
$$

where $R$ is the universal gas constant.

In regard to boundary conditions applied to the temperature field computation, interaction with an 'infinite' surrounding air medium can be expressed through convective/radiative boundary fluxes, as shown in Eq. (9.5), where $T$ is the temperature $\left({ }^{\circ} \mathrm{C}\right), T_{s}$ is the surface 
temperature $\left({ }^{\circ} \mathrm{C}\right)$, and $h_{e q}$ is a convection/radiation coefficient that depends on air speed $(\mathrm{W} / \mathrm{mK})$ :

$$
q=h_{e q}\left(T-T_{s}\right)
$$

\subsection{Thermal Modeling of Phase Change}

The two typical methods that are used for modeling the latent energy storage/release by PCMs are described in the following.

\subsubsection{The Enthalpy-porosity Method}

In order to simulate phase change process, enthalpy-porosity method $[40,41]$ can be used. Bertrand et al. [42] present the results of a comparison exercise in which various numerical approaches were applied to a phase-change problem that included coupled natural convection and melting. The results indicate that enthalpy methods are to be used in most phase-change problems where a solid-liquid interfacial region is present between the phases.

In Eq. (9.3), $S$ is the source term, and $H$ is the specific enthalpy. The latter is defined as a sum of the sensible enthalpy $h=h_{\text {ref }}+\int_{T_{r e f}}^{T} C_{p, n f} d T$, and the enthalpy change due to the phase-change $f L$, where $L$ is the specific enthalpy of melting and $f$ is the liquid fraction during the phase change which occurs over a range of temperatures $T_{\text {Solidus }}<T<T_{\text {Liquidus }}$, defined by the following relations:

$$
f=\left\{\begin{array}{l}
0 \text { if } T<T_{\text {Solidus }} \\
\frac{T-T_{\text {Solidus }}}{T_{\text {Liquidus }}-T_{\text {Solidus }}} \text { if } T_{\text {Solidus }}<T<T_{\text {Liquidus }} \\
1 \text { if } T>T_{\text {Liquidus }}
\end{array}\right.
$$

The source $S_{h}$ of the energy equation is given by:

$$
S_{h}=-\frac{\partial[(\rho L f)]}{\partial t}
$$

The source term $S$ in the momentum equation, is given by

$$
S_{x}=\frac{M(1-f)^{2}}{f^{3}+\varepsilon} u, S_{y}=\frac{M(1-f)^{2}}{f^{3}+\varepsilon} v
$$


where $A(f)=\frac{M(1-f)^{2}}{f^{3}+\varepsilon}$ causes the gradually reduction of the velocities from a finite value in the liquid, to zero in the full solid, over the computational cells that are changing phase. $\varepsilon=0.001$ is a small computational constant used to avoid division by zero, and $M$ is a constant reflecting the morphology of the melting front. This constant is a large number, usually $10^{4}-10^{7}$. In the current study, $M$ is assumed constant and is set to $1.6 \times 10^{6}$.

\subsubsection{The Effective Heat Capacity Method}

The basis of the effective heat capacity method is similar to the enthalpy-porosity method, but instead of directly influencing the enthalpy of the PCM as in Eq. (9.3), it models phase change as a sensible process with an increased (effective) heat capacity [43]. This can be visualized in Figure 9.11.

The effective heat capacity method, similar to the enthalpy-porosity method, defines a new parameter known as the effective heat capacity $\left(C p_{e f f}\right)$ as follows Eq. (9.9) [44]:

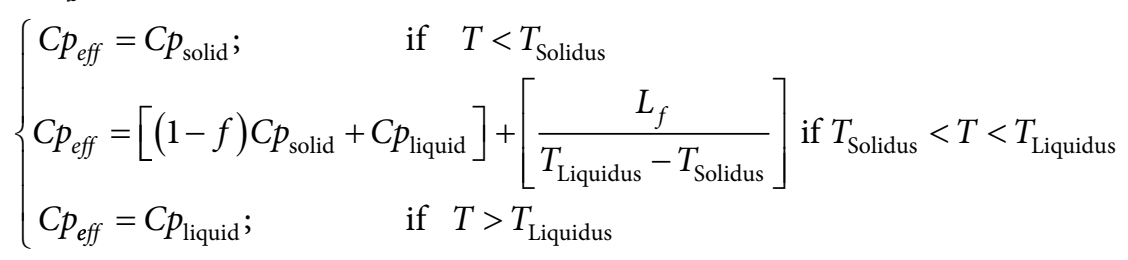

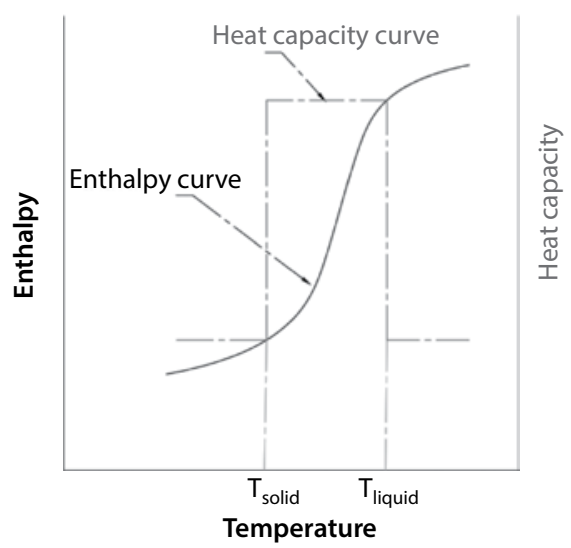

Figure 9.11 Effective heat capacity curve compared with enthalpy curve. 
where $f$ is the liquid fraction defined by Eq. (9.6). Consequently, without explicitly tracking the phase change interface, phase change process can be described by iterating between Eqs (9.6), (9.9), and (9.10) as following expression:

$$
\frac{\partial}{\partial t}\left(\rho C p_{\text {eff }} T\right)+\nabla\left(\rho C p_{e f f} u_{j} T\right)=\nabla(k \nabla T) \pm S_{E}
$$

\subsubsection{Numerical Simulation of Small-scale Prototype}

Numerical simulation of the small-scale prototype with PCM embedded mortar was reported in our previous work [34]. The effective heat capacity method was used to simulate PCM effect. In this way, the effective heat capacity of the PCM as a function of temperature, which was obtained from the DSC measurement, was used in the calculations. In fact, phase changes were modeled through a simplified approach by which the energy release/ absorption associated to the phase change process is considered through artifacts applied to the specific heat capacity term. The computation of the specific heat capacity of the specimen along the tested temperatures $C(T)$ (J/g K) is made according to Eq. (9.11):

$$
C(T)=\frac{\left(\operatorname{DSC}(T)_{\text {Sample }}\right)}{\varphi}
$$

where $D S C(T)_{\text {sample }}$ the heat flow across the specimen at temperature $T$ from the thermogram $(\mathrm{mW} / \mathrm{mg})$, and $\varphi$ is the heating rate $\left({ }^{\circ} \mathrm{C} / \mathrm{s}\right)$. This method allows to implement directly of specific heat capacity curve which is useful since the sensible heat and latent heat are not distinguishable in the DSC output curve (particularly in the hybrid PCM case); therefore, the state of the PCM is not necessary to be defined as all the entire curve is given to the model.

The numerical simulation task was conducted using ANSYS-FLUENT [45] CFD solver. The simulation model of the $0.46 \mathrm{~m} \times 0.46 \mathrm{~m} \times 0.46 \mathrm{~m}$ was simplified using two vertical symmetry planes were considered, leading to the necessity of solely modeling one fourth of the prototype $(0.23 \mathrm{~m} \times 0.23 \mathrm{~m} \times 0.46 \mathrm{~m})$. The generated finite volume mesh for CFD simulations shown in Figure 9.12. The exterior top, bottom and lateral surfaces (except for the symmetry planes), were assigned with convective thermal boundary conditions, taking into account the varying temperature imposed in the climatic chamber. As the prototypes were placed inside an 


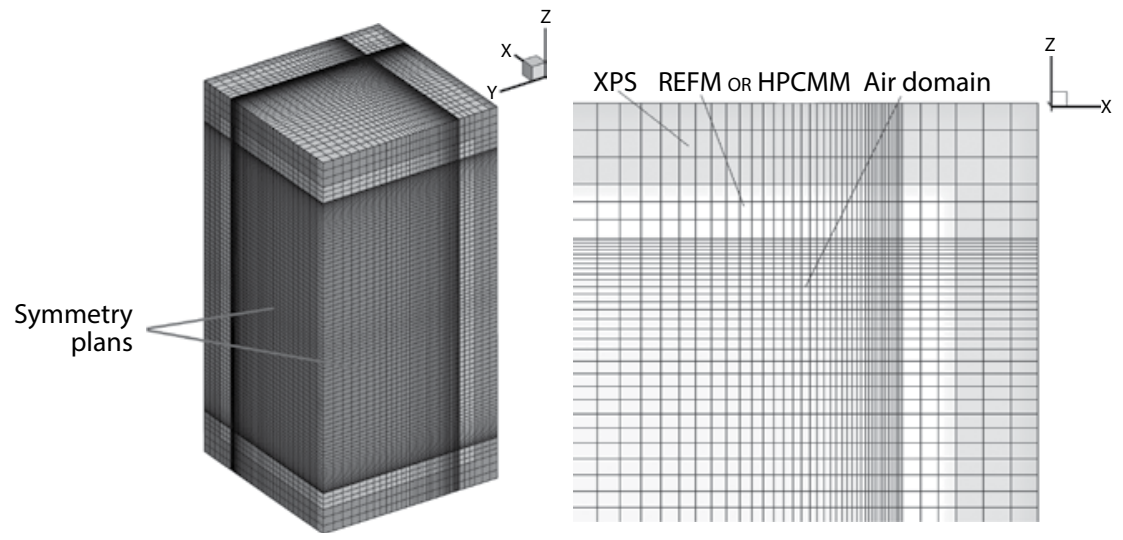

Figure 9.12 Mesh of one-fourth of the numerical thermal model and zoomed mesh distribution in walls and air boundary layer.

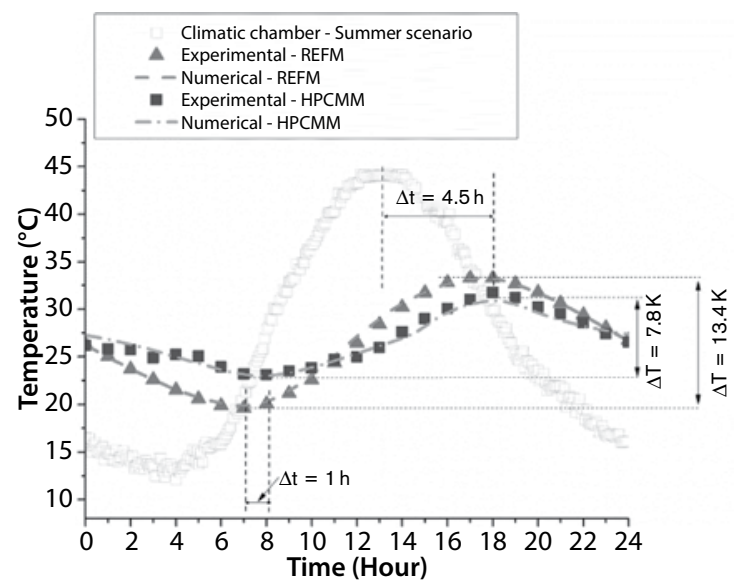

Figure 9.13 Experimental versus numerical values for test cells REFM and HPCMM (summer scenario) [34].

indoor climatic chamber, a value of $h_{e q}=5 \mathrm{~W} / \mathrm{m} \mathrm{K}$ [46] was considered for the surface convection coefficient, in correspondence to near stagnant air conditions.

\subsubsection{Results of the Numerical Simulations of Prototype}

The comparison of experimental and simulation results for prototypes with REFM and with HPCMM is shown in Figure 9.13 for the summer scenario. It can be confirmed that the numerical predictions for the $\mathrm{T}-\mathrm{t}$ evolutions match quite closely the ones measured by the temperature sensor. 
Based on the high confidence level provided by the validations mentioned above, a further simulation was carried out for real-scale dimension, in which we deal with assessing energy saving as well as thermal behavior of the systems with and without incorporation of PCM.

\subsubsection{Case Study of a Simulated Building}

In order to assess the energy efficiency gains for space heating using PCM embedded mortar used as internal coatings for buildings, three test cases of a hypothetical test building were considered in regard to the composition of the interior coating mortar of external walls: (i) in which a hybrid PCM mortar is used (here termed as HPCMM), (ii) the case in which a single PCM mortar is used (here termed as SPCMM), and (iii) the case in which a regular mortar is used (here termed as REFM). The three cases were subjected to similar real temperature variation, thus allowing evaluating the differences in thermal performance induced by the three types of tested mortars which consequently allowing energy saving assessment through real-scale tests.

In the cases with PCM, both SPCMM and HPCMM were considered with nearly $20 \%$ of PCM related to the global mass of the mortar [32]. The formulation of SPCMM adopted herein contains one type of PCM with melting temperature of $24{ }^{\circ} \mathrm{C}$ with quantity reaching $18.34 \%$ of weight within the mortar. The formulation of mortars HPCMM adopted herein contains three distinct PCMs. The HPCMM studied incorporates a combination of three PCMs with melting temperatures of 5,21 , and $23^{\circ} \mathrm{C}$. These three PCMs are considered in equal mass quantity, thus globally reaching $18.34 \%$ of weight within the mortar. The main thermophysical properties of the materials used in all mortar cases, REFM, SPCMM, and HPCMM, are synthesized on Table 9.7, obtained with basis on previous research $[32,34,47]$.

Table 9.7 Thermophysical properties of the materials used in the numerical simulations.

\begin{tabular}{|l|l|l|l|l|c|c|l|}
\hline $\begin{array}{c}\text { Thermophysical } \\
\text { properties }\end{array}$ & Ab. & Units & REFM & HPCMM & XPS & Brick & SPCMM \\
\hline Density & $\rho$ & {$\left[\mathrm{kg} / \mathrm{m}^{3}\right]$} & 1529.5 & 1309.8 & 32 & 1976 & 1360.9 \\
\hline $\begin{array}{c}\text { Thermal } \\
\text { conductivity }\end{array}$ & $\kappa$ & {$[\mathrm{W} / \mathrm{mK}]$} & 0.4 & 0.3 & 0.034 & 0.77 & 0.3 \\
\hline $\begin{array}{c}\text { Specific heat } \\
\text { capacity }\end{array}$ & $C_{p}$ & {$[\mathrm{~J} / \mathrm{kgK}]$} & Figure 9.14 & Figure 9.14 & 1400 & 835 & Figure 9.14 \\
\hline
\end{tabular}




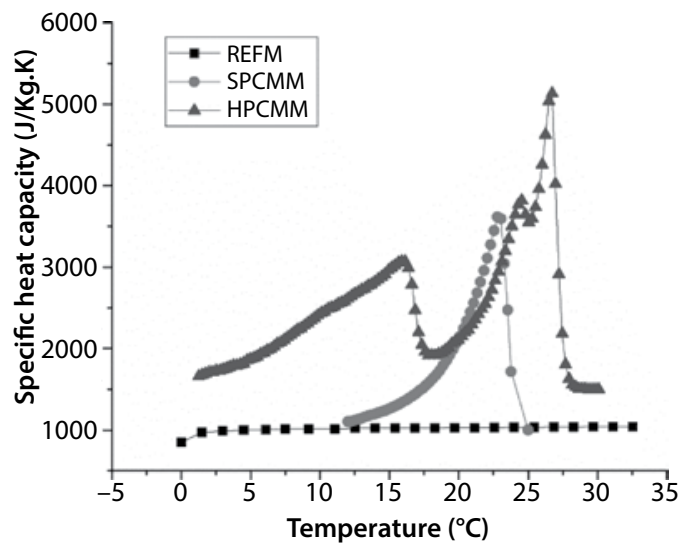

Figure 9.14 Specific heat capacity curves for REFM, SPCMM, and HPCMM.

It is noted that the specific heat capacity of HPCMM was estimated with basis on the results obtained for a similar mortar which had PCM melting temperatures of 10,26 , and $28^{\circ} \mathrm{C}$ [previously tested in [34]] and are presented in Figure 9.14. The specific heat capacity of SPCMM was adopted for a mortar which had PCM melting temperatures of $24^{\circ} \mathrm{C}$ [32].

Table 9.7 also contains information about the XPS, brick [48], and air [49] that were part of the considered wall system. Air was considered as ideal gas with thermal conductivity of $0.0242(\mathrm{~W} / \mathrm{mK})$ and specific heat capacity of $1006.43(\mathrm{~J} / \mathrm{kgK})$.

A simplified five-storey building located in Portugal is considered for simulation - see Figure 9.15a. The entire third floor is analyzed, assuming that no thermal exchanges occur on both bottom and upper slabs (i.e. adiabatic conditions). As shown in Figure 9.15b and c, the volume of study is the third floor with inner dimensions of $9.71 \mathrm{~m}$ (length) $\times 9.71 \mathrm{~m}$ (width) $\times 3 \mathrm{~m}$ (height). The exterior walls, schematically represented in Figure 9.15b, have a typical layout characterized by (from outside to inside): a $0.02 \mathrm{~m}$ thick of plastering mortar (REFM), $0.1 \mathrm{~m}$ of brick, a $0.03 \mathrm{~m}$ of XPS, another $0.1 \mathrm{~m}$ thick of brick and a $0.02 \mathrm{~m}$ of plastering mortar (REFM, SPCMM, or HPCMM) as inner lining. The simulated model equipped with a heater unit that has a heated or cooled area of $3.29 \mathrm{~m}^{2}$ with a power of $1500 \mathrm{~W}$ placed at the geometrical centre of the model. The point labeled as "monitoring point" in Figure 9.15b and c was used as the reference control point for the thermostat of the heating/cooling system and for the temperature analyses presented in this study. The heating/cooling system maintains the internal temperature at the desirable comfort temperature of $20^{\circ} \mathrm{C}$ during winter scenario testing, and $24^{\circ} \mathrm{C}$ during summer 

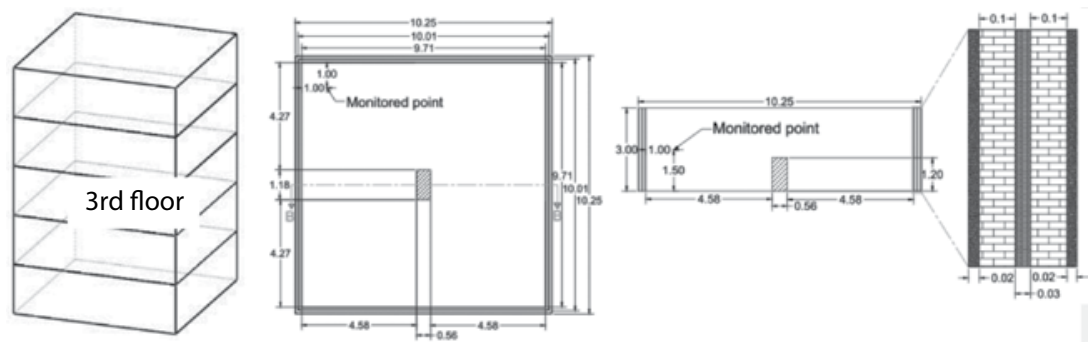

Figure 9.15 Schematic representations of the simulated model: (a) location of the studied floor in the building, (b) plan view, (c) section view B-B, and (d) details of the walls from exterior to the interior (IREFM; brick; XPS; brick; REFM, SPCMM or HPCMM). Units: [m].
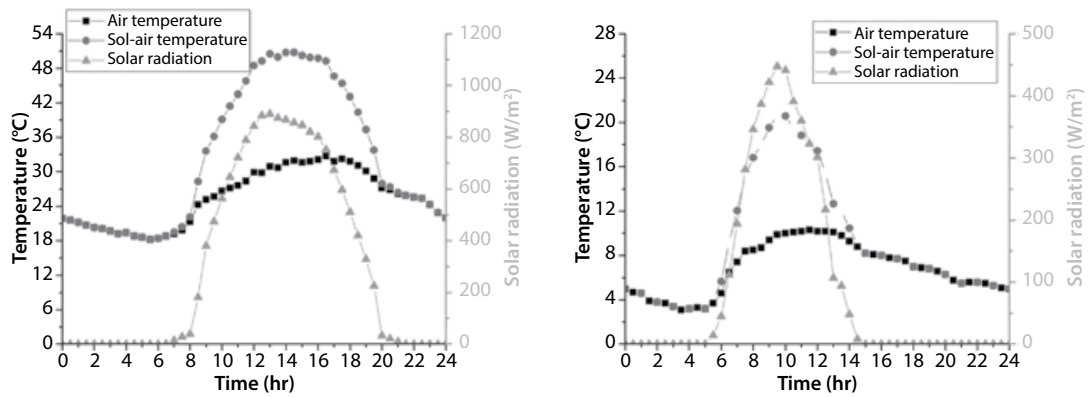

Figure 9.16 Exterior temperature, solar radiation, and sol-air temperature (southoriented wall) for: (a) a summer day and (b) a winter day in Guimarães, Portugal.

scenario testing according to the recommendations of [37]. The operating principle of the thermostat of the heating/cooling system is a simple ON/OFF algorithm. For instance, with the set point of $20^{\circ} \mathrm{C}$ : the heating/ cooling system is turned $\mathrm{ON}$ (heating mode) when the temperature inside becomes lower than $20^{\circ} \mathrm{C}$ and it is turned OFF when the temperature reaches $20^{\circ} \mathrm{C}$ again.

A winter scenario and a summer scenario were studied in this research, corresponding to the location of Guimarães in the North of Portugal. Solar radiation effects were considered in a simplified manner through a sol-air temperature algorithm, according to methodology detailed earlier. As a result of the application of the sol-air temperature algorithm, the 24-h cycles shown in Figure 9.16 were obtained for both summer and winter scenarios.

The exterior lateral surfaces of the walls (except for the top and bottom plans) were assigned with convective thermal boundary conditions, taking into account the varying temperature imposed in the model. In both cases, the model was initialized from $20^{\circ} \mathrm{C}$ for winter scenario and 

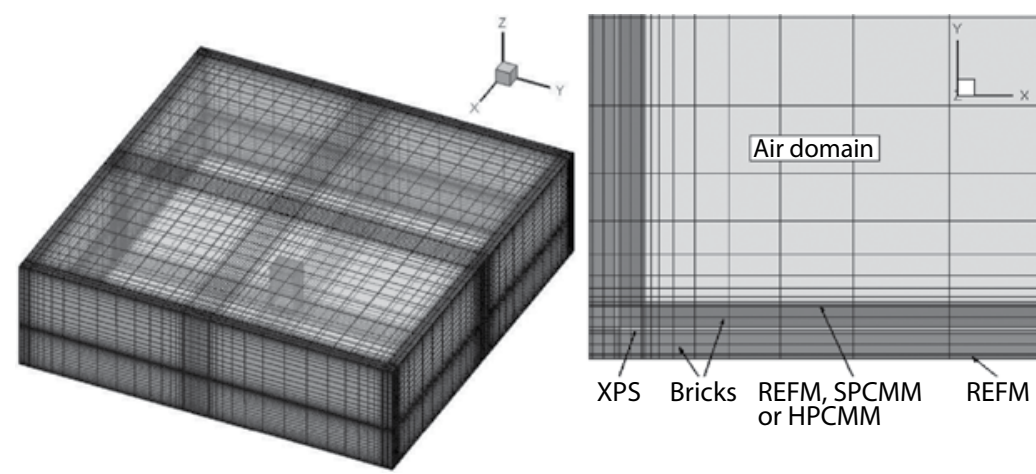

Figure 9.17 Three-dimensional mesh of the simulated model and mesh distribution in walls and air boundary layer.

$24^{\circ} \mathrm{C}$ for summer scenario. A total of three simulations were conducted by submitting each case to summer scenario and winter scenario testing, with each simulation lasting six full day cycles $(144 \mathrm{~h})$. The mesh of the model is structured, being comprised of hexahedral cells as shown in Figure 9.17.

\subsubsection{Results of Thermal Behavior and Energy Saving}

Figure 9.18 shows the temperature variation of the "monitored point" for both winter and summer scenarios for the SPCMM, HPCMM, and REFM cases. In the winter scenario, even though it is not directly noticeable from the figure, the heater is turned on for a total of $6.7 \mathrm{~h}$ per day for the REFM scenario, whereas the SPCMM and HPCMM scenario allowed a reduction of the heating time to 5.5 and $6.4 \mathrm{~h}$, which by itself represents a 17.5 and $4 \%$ saving, respectively. In the summer scenario, the cooler mode was active for a total of $4.7 \mathrm{~h}$ per day for REFM case, while the SPCMM and HPCMM cases reached reduction of the cooling time to 4.3 and $3.5 \mathrm{~h}$, which showed energy savings of 9 and $23.5 \%$, respectively. In this basis, the total amount of energy that can be saved by PCM cases for the HPCMM case reaches to $27.5 \%$ while, for the SPCMM reduction value of $26.5 \%$ was obtained.

Temperature distribution in the interior environment of the buildings becomes important as the building geometries are usually large and complex. In such situations, thermal stratification may become an effective parameter in the enhanced energy design of buildings. In this way, an example of the studied building when it is under winter scenario is assessed to indicate the importance of thermal stratification in the interior 

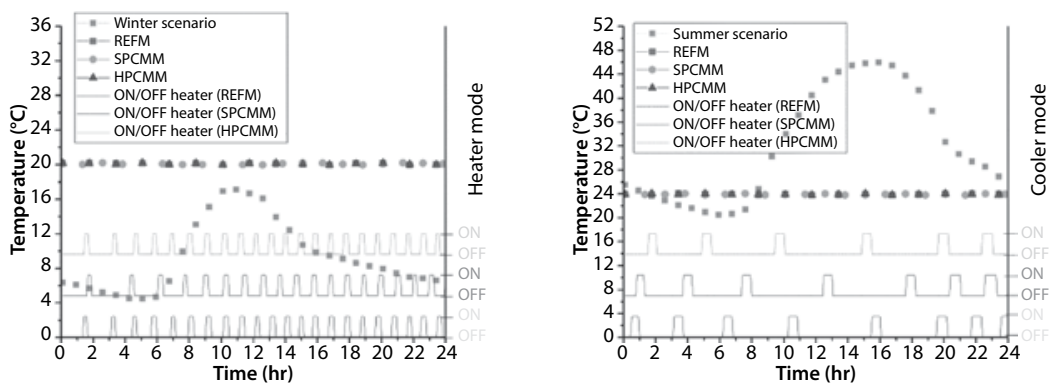

Figure 9.18 Interior temperature of the flats with and PCM controlled with heating/ cooling system: (a) under winter scenario and (b) under summer scenario.

air environments. The interior air temperature of studied building is set to maintain at comfort temperature $\left(20^{\circ} \mathrm{C}\right)$ during winter scenario.

\subsubsection{Global Performance of a Building Systems with Hybrid PCM}

The present section deals with the global performance of the system when it is more close to the realistic situations. In fact, the building usually, is equipped with TV, washing machine, refrigerator, water heater, battery, etc. Therefore, it is advisable to evaluate the performance of the overall system when the hybrid PCM is incorporated. Therefore, a study was considered and analyzed based on household energy management model (HEM). Two cases with hybrid PCM (HPCMM) and without PCM (REFM) were studied. In brief, conceptually, smart grid is the idea to improve the efficiency of the system from producer to the consumer [42]. Buildings may be considered as a smart grid object. Smart buildings can take the advantages of smart grids concept in which, they can minimize the demanded electricity costs.

The target is to minimize the electricity costs for the household when different tariffs are deployed. Demand response programs (DRPs) can play an important role in the future buildings. Because, they can usually shift the peak loads to the off peak load hours. Additionally, PCMs enable to shift the load from peak to off peak electricity consumption period. The combination of PCM into the DRPs can enhance the performance of the system. The aims of DRPs are to assess the sensitivity of variations of electricity prices in different hours.

The importance of the PCM accounted in the DRPs that is given through an example. 
Figure 9.19 represents an example of smart building with group of equipment as a critical loads and controllable loads. The concept of the proposed model can be explained by: during the winter time, the householders use the heating systems during the coldest hours of the day, while, this can increase the demand peak [47].

Figure 9.20 gives residential electricity costs for different tariffs based on the available price list provided by a typical manufacturer company in Portugal called EDP (Energias de Portugal). As it can be seen, there

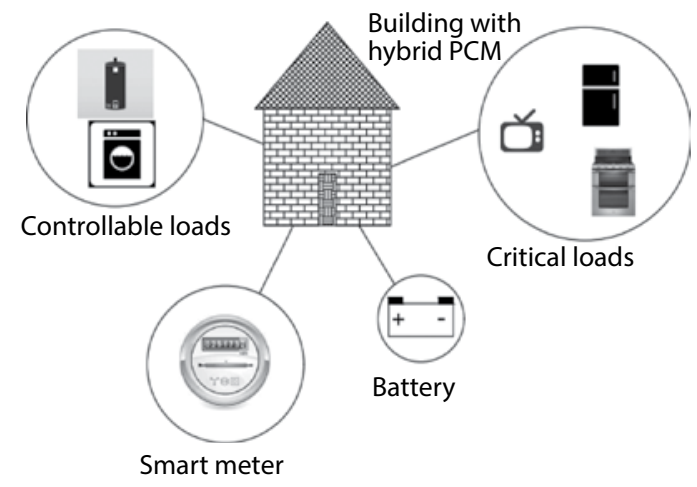

Figure 9.19 Example of a smart building system.

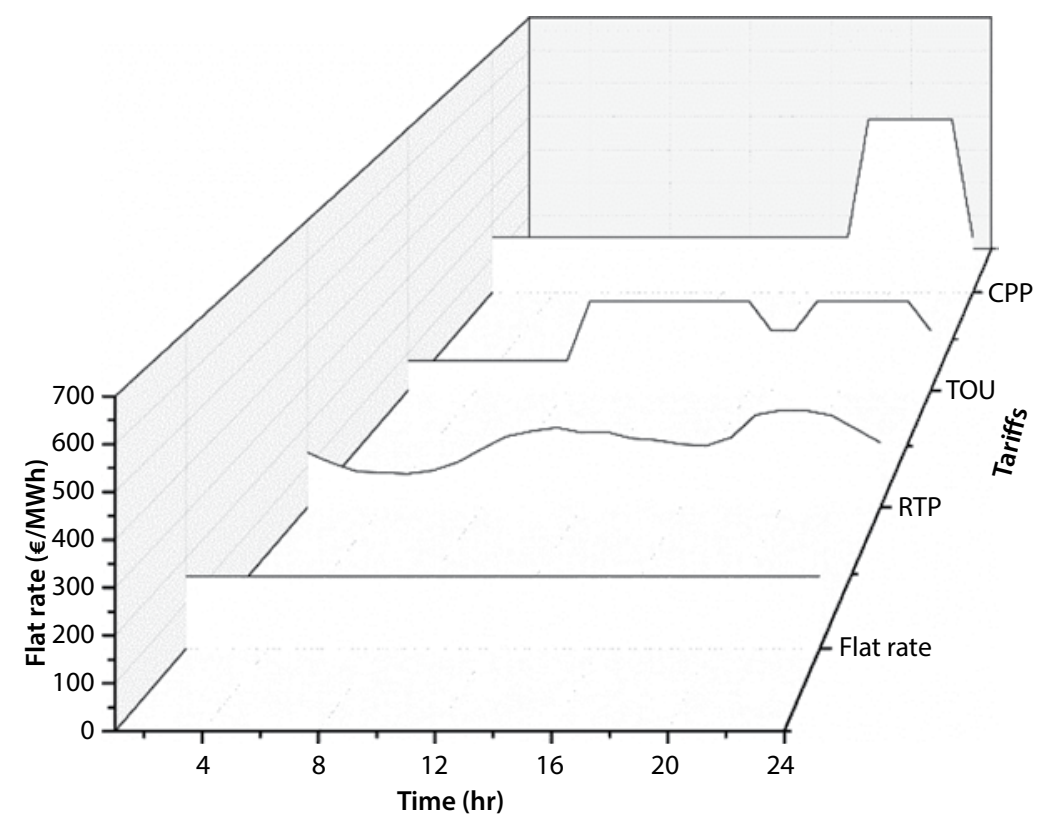

Figure 9.20 Hourly prices of the energy for residential customers [47]. 
are different energy prices at each hours of the day except for flat rate tariff which presents only one value through the entire day. In the following analysis, the study estimates the energy saved by employing PCM mortar into the buildings based on the unit electricity costs for each selected tariff.

Figure 9.21 illustrates the critical load data that were taken from consumption of a typical $100 \mathrm{~m}^{2}$ house is Portugal in winter season. It should be remarked that, HPCMM and REFM are tested in previous section and the results confirmed that the energy consumption for heating the interior in the case with HPCMM is reduced when compared with the REFM. Furthermore, the HPCMM dedicates the shifting of the electricity consumption during entire tested day when compared with REFM as previously shown in Figure 9.18.

The household's cost for one day test considering different DRPs is compared in Figure 9.22. It can be seen, the Critical Peak Pricing (CPP) brings

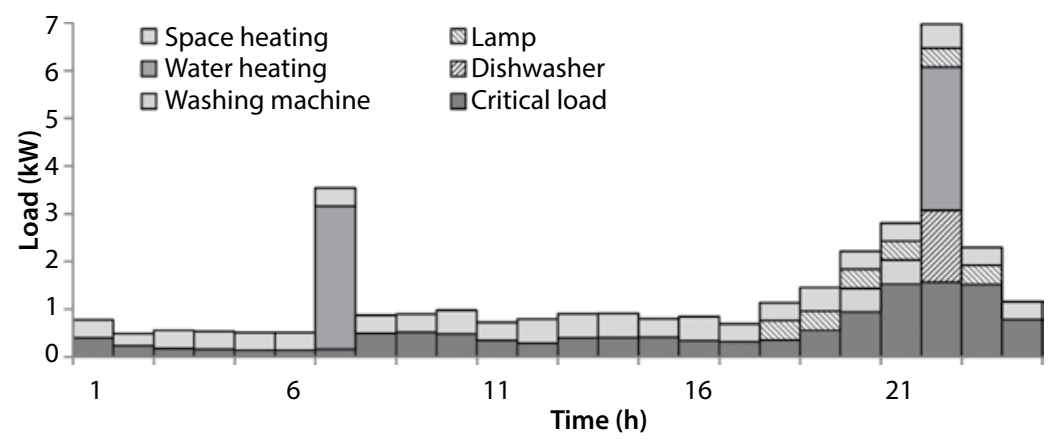

Figure 9.21 Initial household electricity demand [47].

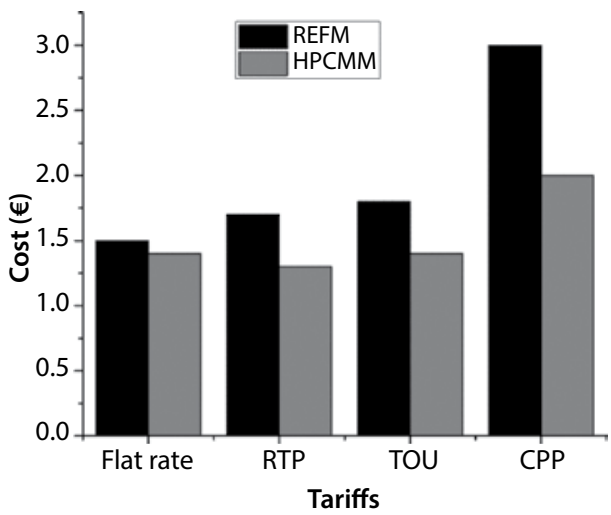

Figure 9.22 Customer's cost in different DRPs during a $24 \mathrm{~h}$. 
significantly higher cost to the household, and however, the proposed model with HPCMM can reduce it by nearly $40 \%$. Different case studies indicated that implementation of HPCMM in the buildings can meaningfully affect the costs of householders in different DRPs.

\subsection{Nanoparticle-enhanced Phase Change Material}

An efficient technique for conservation of thermal energy is to use LHS systems using PCMs. Due to capacity of PCMs for absorption and release of high latent heat during the melting-solidificiation process, they have received a great interest in many applications $[22,23]$.

Many researchers investigated numerous problems pertinent to latent heat TES and utilization in order to improve design and development of an efficient and cost-effective latent heat TES system. Zalba et al. [50] performed a detailed review on heat transfer studies and applications. TES that dealt with PCMs Kenisarin et al. [51] presented a review of on the assessment of the thermal properties of various PCMs, methods of heat transfer enhancement and design configurations of heat storage facilities to be used as a part of different solar systems. Jegadheeswaran et al. [44] reviewed the influence of enhancement techniques on the thermal response of the PCM in terms of phase change rate and amount of latent heat stored/retrieved.

The application PCM that was discussed in the previous section was mostly for the cases that one need to control the temperature of an environment to a desired value. In those applications, low thermal conductivity of phase change material benefits the thermal regulation process. However, employing PCM in the context of building energy saving is not only limited to control the temperature of environments.

PCMs can be used as a means of saving energy in cooling and heating systems of buildings such as solar water heaters, heat exchangers, etc. In addition, for the internal wall of the building, PCMs do not need to have necessarily low thermal conductives. TES density and storage capacity are very important specification of a TES system. In these applications, as much as the heat/energy transfer occurs faster, the energy saving efficiency would increase. If the thermal conductivity of the PCM increase, heat will be transferred in a faster rate and consequently phase change (solidification/melting) will occur faster. This means that phase change elements will absorb the extra energy, and we can be sure that all the energy saving capacity of the PCM is used. In other words, the dynamic performance and the thermal power delivery is closely associated with the heat transfer 
within the heat storage materials, which means that high charge/discharge thermal power signifies fast heat transfer within the storage materials.

PCMs suffer from having low thermal conductivities which lead to decreasing the rates of heat storage and retrieval during melting and solidification processes that in turn limit their utility areas. To overcome this major drawback, a wide range of investigations were carried out to enhance the thermal conductivity of the organic PCMs or increase heat transfer performance. Conductivity enhancement can be done in a number of ways including the use of nanoparticles. The enhanced PCM (nanofluid) is found to exhibit lengthened melting times and shortened cool-down times. The presence of the nanoparticles in the fluids increases appreciably the effective thermal conductivity of the fluid and consequently enhances the heat transfer characteristics [52-55]. The nanoparticles embedded into the pure PCM may create more thermal conductive interfaces within the PCM matrix layers. A review of the unique features of nanofluids, such as enhancement of heat transfer, improvement in thermal conductivity, increase in surface volume ratio, Brownian motion, thermophoresis and in addition, the outline of the recent research in experimental and theoretical studies on forced and free convective heat transfer in nanofluids, their thermophysical properties and their applications is performed Godson et al. [56]. Khodadadi et al. [57] reported an improved functionality of PCMs through dispersion of nanoparticles. They found that the resulting nanoparticle-enhanced phase change materials (NEPCM) exhibit enhanced thermal conductivity in comparison to the base material. Ranjbar et al. [58] investigated the influence of utilizing nanoparticle on enhancement of heat transfer in a three-dimensional cavity. Khodadadi et al. [43] utilized an analytic/integral approach to solve a one-dimensional Stefan problem for a nanofluid that undergoes freezing. Their model accounts for the thermal property jumps between the liquid and solid phases and showed that the freezing time decreases as the volume fraction of the nanoparticle is raised. There are only few published experimental data that are addressing the use of nano-particles in order to enhance PCMs. Wu et al. [59] developed a new sort of nanofluid phase change material by suspending a small amount of nanoparticles in melting paraffin. They selected $\mathrm{Cu}, \mathrm{Al}$, and $\mathrm{C} / \mathrm{Cu}$ nanoparticles added to the melting paraffin to enhance the heat transfer rate of paraffin, $\mathrm{Cu}$ nanoparticles had the best performance for heat transfer. Wu et al. [59] studied the potential of $\mathrm{Al}_{2} \mathrm{O}_{3}-\mathrm{H}_{2} \mathrm{O}$ nanofluids as a new PCM for the TES of cooling systems. The thermal response test showed that addition of $\mathrm{Al}_{2} \mathrm{O}_{3}$ nanoparticles remarkably decreases the supercooling degree of water, advances the beginning freezing time and reduces the total freezing 
time. They showed that only adding $0.2 \mathrm{wt} \% \mathrm{Al}_{2} \mathrm{O}_{3}$ nanoparticles, the total freezing time of $\mathrm{Al}_{2} \mathrm{O}_{3}-\mathrm{H}_{2} \mathrm{O}$ nanofluids can be reduced by $20.5 \%$.

In our previous works $[60,61]$, we analyzed and demonstrated the enhancement of heat storage capacity of a thermal system based on PCM through a numerical case study. The heat transport in the PCM of thermal systems such as solar water heater normally includes both natural convection and conduction heat transfer. Here, we briefly report the results of the numerical study of the thermal behavior of $\mathrm{Cu}$-water nanofluid (as a nominal PCM) during solidification in an enclosure. Influence of natural convection along with the impacts of nanoparticle volume fraction is studied in details. Results are presented for the selected range of Grashof number $\left(G r=10^{4}, 10^{5}, 10^{6}\right)$, and nanoparticle volume fraction $(\phi=0,0.05,0 .$,$) . For simulation, we used small value of nanoparticle$ volume fraction. High values of volume fraction will make nanoparticles easier to aggregate thus at those high concentrations the nanofluid is unstable and thus cannot be used in such a hostile environment of melting and freezing.

\subsubsection{Modeling nanoparticle-enhanced PCM}

We assume that addition of the nanoparticle to the PCM changes the properties of the resulting material. Considering the mixture of nanoparticle and PCM (nanofluid) as a continuous media with thermal equilibrium between the base fluid and the solid nanoparticles, The density of the nanofluid is given by

$$
\rho_{n f}=(1-\phi) \rho_{f}+\phi \rho_{S}
$$

Whereas the heat capacitance an the thermal expansion coefficient of the nanofluid are

$$
\begin{gathered}
\left(\rho C_{P}\right)_{n f}=(1-\phi)\left(\rho C_{P}\right)_{f}+\phi\left(\rho C_{P}\right)_{S} \\
(\rho \beta)_{n f}=(1-\phi)(\rho \beta)_{f}+\phi(\rho \beta)_{S}
\end{gathered}
$$

The latent heat of nanofluid is evaluated using [62]:

$$
(\rho L)_{n f}=(1-\phi)(\rho L)_{f}
$$

with $\phi$ being the volume fraction of the solid particles and subscripts $f, n f$, and $s$ stand for base fluid, nanofluid, and solid, respectively. The effective 
dynamic viscosity of the nanofluid containing a dilute suspension of small rigid spherical particles is given by [63] as:

$$
\mu_{n f}=\frac{\mu_{f}}{(1-\phi)^{2.5}}
$$

whereas the thermal conductivity of the stagnant (subscript 0 ) nanofluid and the effective thermal conductivity of the nanofluid according to [64] are:

$$
\frac{k_{n f 0}}{k_{f}}=\frac{k_{s}+2 k_{f}-2 \phi\left(k_{f}-k_{s}\right)}{k_{s}+2 k_{f}+\phi\left(k_{f}-k_{s}\right)}, k_{e f f}=k_{n f 0}+k_{d}
$$

and the thermal conductivity enhancement term due to thermal dispersion is given by

$$
k_{d}=C\left(\rho C_{P}\right)_{n f} \sqrt{u^{2}+v^{2} \phi d_{P}}
$$

The empirically determined constant $\mathrm{C}$ is evaluated following the work of Wakao et al. [65].

\subsubsection{Definition of the Case study}

Consider a two-dimensional cavity with vertical wavy wall of height and average width of $\mathrm{H}$, with amplitude of the wavy wall as shown in Figure 9.23. The inner space of the cavity is filled with the $\mathrm{Cu}$-water nanofluid as PCM. It was assumed that the flow is steady, and that the base fluid and the nanoparticles are in thermal equilibrium and no slip occurs between them.
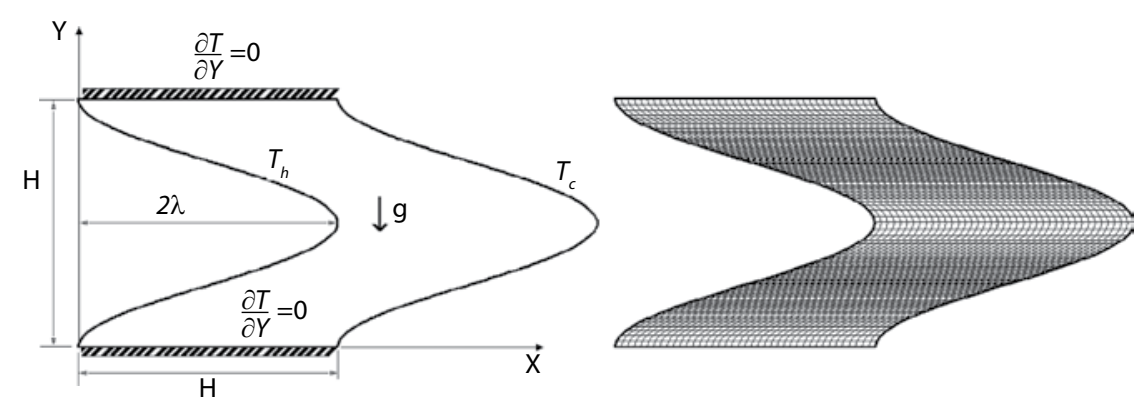

Figure 9.23 Sketch of the vertical wavy enclosure $[60,61]$. 
Table 9.8 Thermophysical properties of the $\mathrm{Cu}$ nanoparticles and base fluid (water).

\begin{tabular}{|l|c|c|}
\hline & Cu nanoparticle & Base fluid(water) \\
\hline $\boldsymbol{\rho}\left[\mathbf{k g} / \mathbf{m}^{3}\right]$ & $\mathbf{8 9 5 4}$ & $\mathbf{9 9 7 . 1}$ \\
\hline $\boldsymbol{\mu}[\mathbf{P a ~ s}]$ & - & $\mathbf{8 . 9 e - 4}$ \\
\hline$c p[J / K g K]$ & 383 & 4179 \\
\hline \multirow{2}{*}{$k[W / m K]$} & \multirow{2}{*}{400} & $k_{\text {liquid }}=\mathbf{0 . 6}$ \\
\cline { 2 - 3 } & & $k_{\text {ice }}=\mathbf{2 . 3}$ \\
\hline$L[J / K g]$ & - & 335000 \\
\hline $\mathbf{P r}$ & - & $\mathbf{6 . 2}$ \\
\hline$d_{p}[m]$ & $10^{-9}$ & - \\
\hline $\boldsymbol{\beta}\left[K^{-1}\right]$ & $1.67 \times \mathbf{1 0}^{-5}$ & $2.1 \times 10^{-4}$ \\
\hline
\end{tabular}

Thermophysical properties of the nanofluid are assumed to be constant except for the density variation, which is approximated by the Boussinesq model. The thermophysical properties of the base fluid and nanoparticle which were used for simulation are given in Table 9.8.

The upper and lower walls of the cavity are horizontal and kept adiabatic. The vertical walls are wavy and the surface wave shape is followed by

$$
\begin{aligned}
& 0 \leq y \leq H \\
& X=\left\{\begin{array}{l}
-\lambda\left(1-\cos \left(\frac{2 \pi y}{H}\right)\right. \text { for left wall } \\
1+\lambda\left(1-\cos \left(\frac{2 \pi y}{H}\right)\right. \text { for right wall }
\end{array}\right.
\end{aligned}
$$

It should be noted that for all values of $\lambda$ at each Grashof number, the inter area of the enclosure is constant. Vertical walls are kept isothermal. The gravity acceleration $g$ acts vertically downward. No slip boundary condition is applied for velocity components at both horizontal and vertical walls.

\subsubsection{Results of Case Study with Nanoparticle-enhanced Phase Change Material}

In order to validate the implementation of mathematical model of melting and solidification in our finite volume CFD code, numerical simulation 


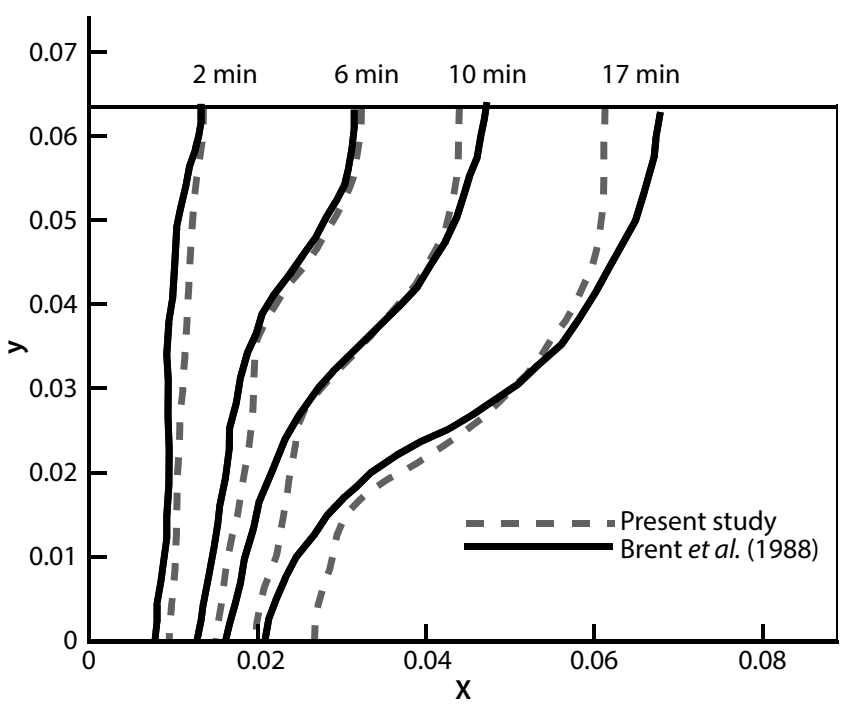

Figure 9.24 Progress of melting phase front with time: comparison among predictions of [40] and present work.

of melting of gallium [40] is considered and the comparison of the phase front propagation is demonstrated in Figure 9.24. A reasonably good agreement is obtained.

Numerical modeling of phase change process (solidification) starts with steady natural convection within a $\mathrm{Cu}$-water nanofluid inside an enclosure with the cold wall temperature being at the freezing temperature of base fluid $(273.15 \mathrm{~K})$ and the hot wall $10 \mathrm{~K}$ upper than $T_{c}$. Then the temperatures of the left and right walls were lowered by $10 \mathrm{~K}$. Consequently, the freezing of the nanofluid will start on the cold wall.

Heat transfer rate of mixture of nanoparticles and PCM is presented in terms of local and average Nusselt number. Local Nusselt number $\left(N u_{L}\right)$ is calculated from the following equation:

$$
N u_{L}=\left.\frac{k_{n f}}{k_{f}} \frac{H}{\Delta T} \frac{\partial T}{\partial n}\right|_{w}
$$

Average Nusselt number is calculated by integrating local Nusselt number distribution using the following equation:

$$
N u_{\text {ave }}=\frac{1}{S} \int_{0}^{s} N u_{L} d s
$$


where $s$ is the distance along the wavy wall and $S$ is the total length of the wavy wall. Figure 9.25 presents the variation of average Nusselt number with surface waviness using different volume fraction of $\mathrm{Cu}$ nanoparticle and different values of Grashof number at $t=0 \mathrm{~s}$. The figure shows that the heat transfer improves with increasing the volume fraction for all Grashof numbers. The $\mathrm{Cu}$ nanoparticles have high values of thermal conductivity and, therefore, this enhances the rates of heat transfer. As volume fraction of nanoparticles increases, difference between mean Nusselt number becomes larger especially at higher Grashof numbers due to domination of convection mode of heat transfer.

The heat transfer phenomena concerned with freezing consists of both the convective and conductive mode of energy transfer. At the beginning of the solidification process, convection is still coexisting with conduction in liquid phase and thus the difference in phase velocities is obvious. But soon after, convection would be negligible and the heat transfer mechanism is mainly due to conduction.

The dependency of liquid volume fraction of the nanofluid with the solid particle volume fraction of the dispersed nanoparticles is represented in Figure 9.26. As the solid particle volume fraction is raised the freezing time is lowered. This is due to the enhanced thermal conductivity of the nanofluid in comparison to that of the base liquid. At the same time, due to lowering of the latent heat of fusion, less energy per unit mass of the nanofluid is needed for freezing. The performance enhancement of NEPCM is due to shortening of solidification time. However, the undesirable loss of capacity, which is another important concern of the performance, must be considered as well, especially when the solid particle volume fraction is high.
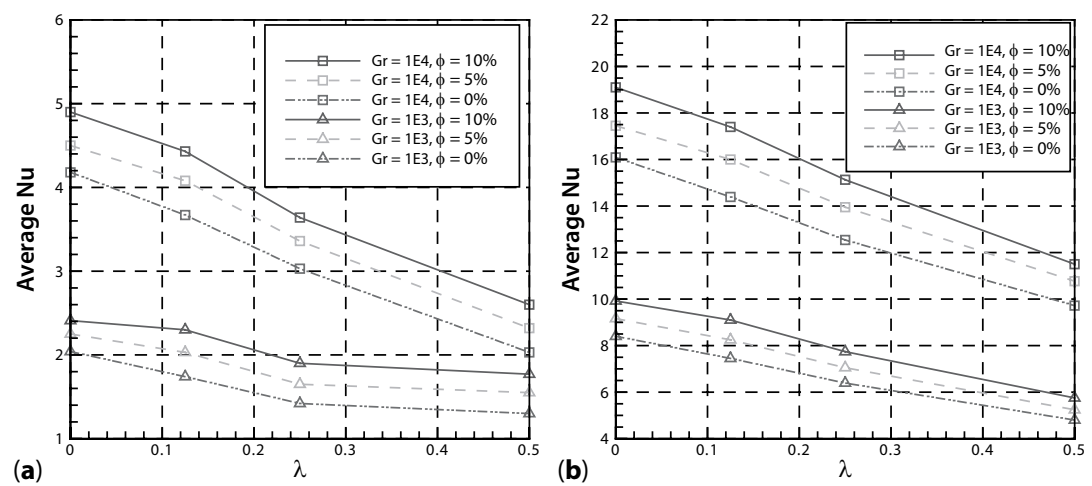

Figure 9.25 Total heat transfer enhancement of nanoparticle for various Gr and surface waviness. 


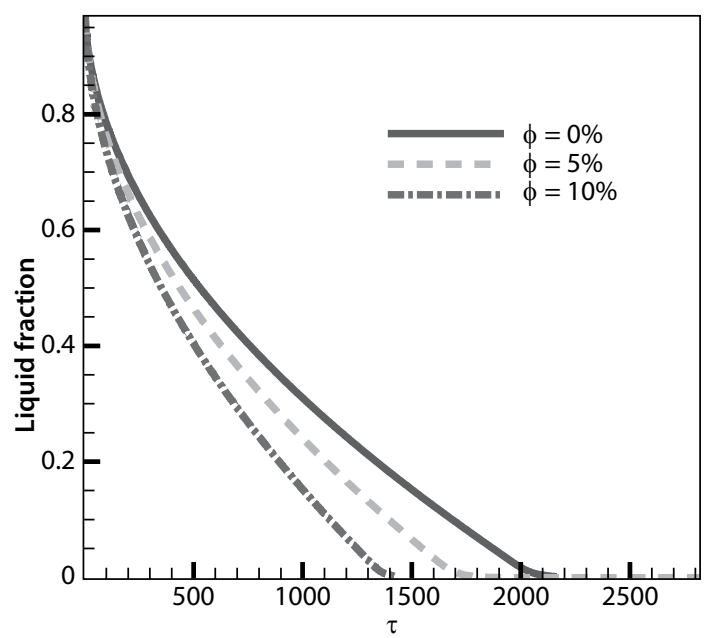

Figure 9.26 Effects of nanoparticle volume fraction on solidification time.

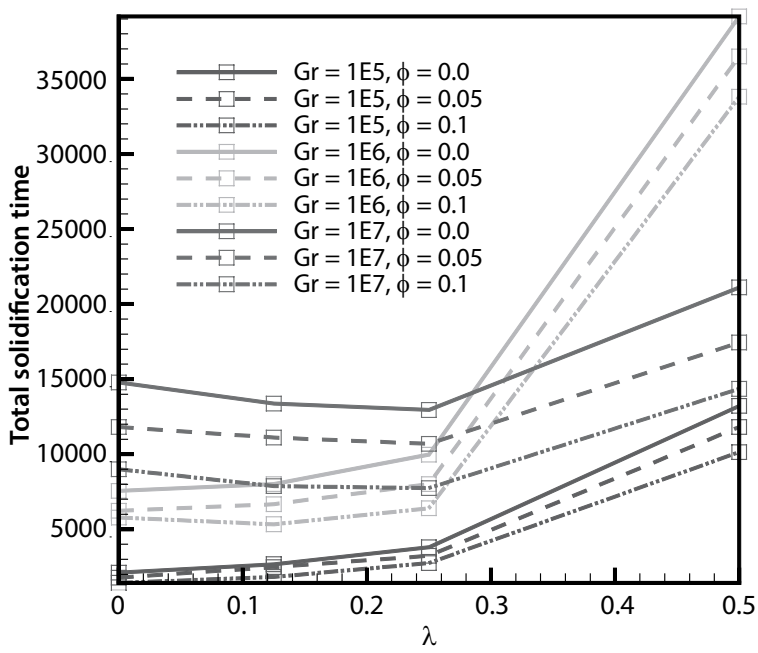

Figure 9.27 Total solidification time for different surface waviness at different Gr number with different nanoparticles volume fraction.

PCM can be used for mainly two distinct applications, TES and thermal regulation (applications high thermal inertia), respectively. For the first, fast phase change process is desirable but for the second one, a phase change process with lengthened solidification time is needed. Figure 9.27 shows the effects of different parameter on solidification time. Increasing nanoparticle volume fraction is effective in decreasing solidification time for all the cases. 


\subsection{Conclusions (General Remarks)}

The experimental and numerical approaches followed in this work provide a detailed ground for improvement of energy saving using the PCM for building application purposes. In view of the obtained results, following observations may be summarized:

- This study basically focused on specific enthalpy estimation and phase change temperature for PCM mortars and pure PCM samples as important parameters of thermal characterization. The results showed that the mixture of two PCMs has a similar behavior to the superposition of effects of independent PCMs. Therefore, it can be inferred that the two PCMs did not have thermal interaction with each other. Furthermore, it was observed that the specific enthalpy is linearly proportional to the mass fraction of PCM in the mortar sample as compared to the behavior of plain PCM samples.

- In this study, a set of experiments and numerical simulations were performed in order to demonstrate the transient thermal behavior of plastering mortars containing hybrid PCM blends, as compared to the behavior of regular mortars, or those containing a single type of PCM. It was also inferred that the utilization of hybrid PCM blends has revealed the capacity to better attenuate daily environmental thermal amplitudes within the test cells as compared to any of the other studied alternatives (reference mortar). It is remarked that the use of more than one type of PCM in the mortar has revealed adequate thermal behavior, being consistent with the predictable outcome of the two incorporated PCMs used individually at the same proportions. The hybrid blend of two distinct types of PCM proved advantageous for improved thermal comfort assurance in buildings (reducing energy consumption for heating/cooling seasons), and their feasibility at material/thermal level was evaluated in this work.

- Numerical study on the nano-enhanced PCM pointed that the concept of blending nanoparticles and PCM leads to increase in thermal performance. Results showed that dispersion of nanoparticle in a PCM will alter the thermophysical properties of the mixture leading to the decrease in 
solidification time of PCM. This means that nano-enhanced PCM can respond to the thermal variations faster than pure PCM materials. In other words, it is concluded that energy saving systems based on nano-enhanced PCMs could save energy with a more efficient rate.

\section{References}

1. Baetens R, Jelle BP, Gustavsen A. Phase change materials for building applications: A state-of-the-art review. Energy and Buildings. 42(9), 1361-8, 2010.

2. Sarı A, Sarı H, Önal A. Thermal properties and thermal reliability of eutectic mixtures of some fatty acids as latent heat storage materials. Energy conversion and management. 45(3), 365-76, 2004.

3. Shilei L, Guohui F, Neng Z, Li D. Experimental study and evaluation of latent heat storage in phase change materials wallboards. Energy and buildings. 39(10), 1088-91, 2007.

4. Kuznik F, Virgone J, Roux J-J. Energetic efficiency of room wall containing PCM wallboard: a full-scale experimental investigation. Energy and buildings. 40(2), 148-56, 2008.

5. Kuznik F, Virgone J. Experimental assessment of a phase change material for wall building use. Applied Energy. 86(10), 2038-46, 2009.

6. Ahmad M, Bontemps A, Sallée H, Quenard D. Thermal testing and numerical simulation of a prototype cell using light wallboards coupling vacuum isolation panels and phase change material. Energy and Buildings. 38(6), 673-81, 2006.

7. Castell A, Martorell I, Medrano M, Pérez G, Cabeza LF. Experimental study of using PCM in brick constructive solutions for passive cooling. Energy and Buildings. 42(4), 534-40, 2010.

8. Sá AV, Azenha M, de Sousa H, Samagaio A. Thermal enhancement of plastering mortars with phase change materials: experimental and numerical approach. Energy and Buildings. 49, 16-27, 2012.

9. Gómez MA, Álvarez Feijoo MA, Comesaña R, Eguía P, Míguez JL, Porteiro J. CFD simulation of a concrete cubicle to analyze the thermal effect of phase change materials in buildings. Energies. 5(7), 2093-111, 2012.

10. Pasupathy A, Velraj R. Effect of double layer phase change material in building roof for year round thermal management. Energy and Buildings. 40(3), 193-203, 2008.

11. Bentz DP, Turpin R. Potential applications of phase change materials in concrete technology. Cement and Concrete Composites. 29(7), 527-32, 2007.

12. Fath HE. Technical assessment of solar thermal energy storage technologies. Renewable Energy. 14(1), 35-40, 1998.

13. Duffie JA, Beckman WA. Solar engineering of thermal processes: Wiley New York etc., 1980. 
14. Cao S. [master thesis], State of the art thermal energy storage solutions for high performance buildings, University of Jyväskylä. 2010.

15. Dutil Y, Rousse DR, Salah NB, Lassue S, Zalewski L. A review on phasechange materials: mathematical modeling and simulations. Renewable and sustainable Energy reviews. 15(1), 112-30, 2011.

16. Zhou D, Zhao C-Y, Tian Y. Review on thermal energy storage with phase change materials (PCMs) in building applications. Applied energy. 92, 593-605, 2012.

17. Sharma A, Tyagi V, Chen C, Buddhi D. Review on thermal energy storage with phase change materials and applications. Renewable and Sustainable energy reviews. 13(2), 318-45, 2009.

18. Cabeza LF, Castell A, Barreneche C, de Gracia A, Fernández AI. Materials used as PCM in thermal energy storage in buildings: A review. Renewable and Sustainable Energy Reviews. 15(3), 1675-95, 2011.

19. Kośny J, Yarbrough DW, Riazzi T, Leuthold D, Smith JB, Bianchi M. Development and testing of ignition resistant microencapsulated phase change material. Proceedings of the Effstock. 2009.

20. Velraj R, Pasupathy A. Phase change material based thermal storage for energy conservation in building architecture. Institute for Energy Studies, CEG, Anna University, Chennai. 2003.

21. Abhat A. Low temperature latent heat thermal energy storage: Heat storage materials. Solar Energy. 30(4), 313-32, 1983.

22. Zhang H, Baeyens J, Degrève J, Cáceres G, Segal R, Pitié F. Latent heat storage with tubular-encapsulated phase change materials (PCMs). Energy. 76, 66-72, 2014.

23. Wang Y-H, Yang Y-T. Three-dimensional transient cooling simulations of a portable electronic device using PCM (phase change materials) in multi-fin heat sink. Energy. 36(8), 5214-24, 2011.

24. Hawes DW, Banu D, Feldman D. Latent heat storage in concrete. Solar energy materials. 19(3), 335-48, 1989.

25. Tyagi V, Kaushik S, Tyagi S, Akiyama T. Development of phase change materials based microencapsulated technology for buildings: a review. Renewable and Sustainable Energy Reviews. 15(2), 1373-91, 2011.

26. Soares N, Costa J, Gaspar A, Santos P. Review of passive PCM latent heat thermal energy storage systems towards buildings' energy efficiency. Energy and buildings. 59, 82-103, 2013.

27. Kheradmand M, de Aguiar JB, Azenha M. Estimation of the specific enthalpytemperature functions for plastering mortars containing hybrid mixes of phase change materials. International Journal of Energy and Environmental Engineering. 5(1), 1-7, 2014.

28. Microthermic THERMIC Temperature Regulation Technology http://www. devan.net/DEVAN Chemicals Portugal 2012.

29. Cunha SRL, Aguiar JLBd, Kheradmand M, Bragança L, Ferreira VM, Tadeu A. Thermal mortars: contribution of the incorporation of PCM microcapsules. 2012. 
30. Cunha S, Aguiar J, Ferreira V, Tadeu A. Mortars based in different binders with incorporation of phase-change materials: Physical and mechanical properties. European Journal of Environmental and Civil Engineering. 19(10), 1216-33, 2015.

31. Taylor HFW. Cement Chemistry: Thomas Telford, 1997.

32. Kheradmand M, Azenha M, de Aguiar JLB, Krakowiak KJ. Thermal behavior of cement based plastering mortar containing hybrid microencapsulated phase change materials. Energy and Buildings. 84, 526-36, 2014.

33. Goldstein JI, Newbury DE, Echlin P, Joy DC, Romig Jr A, Lyman CE, et al. Electron optics. Scanning Electron Microscopy and X-Ray Microanalysis: Springer; pp. 21-68, 1992.

34. Kheradmand M, Azenha M, de Aguiar JL, Castro-Gomes J. Experimental and numerical studies of hybrid PCM embedded in plastering mortar for enhanced thermal behaviour of buildings. Energy. 94, 250-61, 2016.

35. Rubitherm $\mathrm{GmbH}$ phase change material manufacturer company- RT series http://www.rubitherm.eu/ Germany 2012.

36. BASF chemical. Polyacrylic dispersions products: Acronal brand, https:// www.dispersions-pigments.basf.com/portal/basf/ien/dt.jsp, Germany. 2016.

37. ASHRAE55. Thermal Environment Standards for Human Occupancy. 55. Atlanta G, 2004.

38. Chen Q. Ventilation performance prediction for buildings: A method overview and recent applications. Building and Environment. 44(4), 848-58, 2009.

39. Gowreesunker B, Tassou S. Effectiveness of CFD simulation for the performance prediction of phase change building boards in the thermal environment control of indoor spaces. Building and Environment. 59, 612-25, 2013.

40. Brent AD, Voller VR, Reid KJ. Enthalpy-Porosity technique for modeling convection-diffusion phase change: application to the melting of a pure metal. Numerical Heat Transfer. 13(3), 297-318, 1988.

41. Gong Z-X, Devahastin S, Mujumdar AS. Enhanced heat transfer in free convection-dominated melting in a rectangular cavity with an isothermal vertical wall. Applied Thermal Engineering. 19(12), 1237-51, 1999.

42. Bertrand O, Binet B, Combeau H, Couturier S, Delannoy Y, Gobin D, et al. Melting driven by natural convection A comparison exercise: first results. International Journal of Thermal Sciences. 38(1), 5-26, 1999.

43. Khodadadi J, Fan L. Expedited freezing of nanoparticle-enhanced phase change materials (NEPCM) exhibited through a simple 1-D stefan problem formulation. Conference Expedited freezing of nanoparticle-enhanced phase change materials (NEPCM) exhibited through a simple 1-D stefan problem formulation. American Society of Mechanical Engineers, p. 345-51.

44. Jegadheeswaran S, Pohekar SD. Performance enhancement in latent heat thermal storage system: a review. Renewable and Sustainable Energy Reviews. 13(9), 2225-44, 2009.

45. ANSYS FLUENT. User guid Release 16.0, 2015. 
46. Azenha M. Numerical simulation of the structural behaviour of concrete since its early ages [PhD thesis] University of Porto Portugal.

47. Shafie-khah M, Kheradmand M, Javadi S, Azenha M, de Aguiar J, CastroGomes J, et al. Optimal behavior of responsive residential demand considering hybrid phase change materials. Applied Energy. 163, 81-92, 2016.

48. Vicente R, Silva T. Brick masonry walls with PCM macrocapsules: an experimental approach. Applied Thermal Engineering. 67(1), 24-34, 2014.

49. Incropera FP, Bergman TL, DeWitt DP, Lavine AS. Fundamentals of Heat and Mass Transfer: Wiley, 2013.

50. Zalba B, Marín JM, Cabeza LF, Mehling H. Review on thermal energy storage with phase change: materials, heat transfer analysis and applications. Applied thermal engineering. 23(3), 251-83, 2003.

51. Kenisarin M, Mahkamov K. Solar energy storage using phase change materials. Renewable and Sustainable Energy Reviews. 11(9), 1913-65, 2007.

52. Esmaeilpour M, Abdollahzadeh M. Free convection and entropy generation of nanofluid inside an enclosure with different patterns of vertical wavy walls. International Journal of Thermal Sciences. 52, 127-36, 2012.

53. Rahimi M, Ranjbar A, Hosseini M, Abdollahzadeh M. Natural convection of nanoparticle-water mixture near its density inversion in a rectangular enclosure. International Communications in Heat and Mass Transfer. 39(1), 131-7, 2012.

54. Moh'd A A-N, Al-Dafaie AMA. Using nanofluids in enhancing the performance of a novel two-layer solar pond. Energy. 68, 318-26, 2014.

55. Ting TW, Hung YM, Guo N. Entropy generation of nanofluid flow with streamwise conduction in microchannels. Energy. 64, 979-90, 2014.

56. Godson L, Raja B, Lal DM, Wongwises S. Enhancement of heat transfer using nanofluids-an overview. Renewable and sustainable energy reviews. 14(2), 629-41, 2010.

57. Khodadadi J, Hosseinizadeh S. Nanoparticle-enhanced phase change materials (NEPCM) with great potential for improved thermal energy storage. International Communications in Heat and Mass Transfer. 34(5), 534-43, 2007.

58. Ranjbar AA, Kashani S, Hosseinizadeh SF, Ghanbarpour M. Numerical heat transfer studies of a latent heat storage system containing nano-enhanced phase change material. Thermal Science. 15(1), 169-81, 2011.

59. Wu S, Zhu D, Zhang X, Huang J. Preparation and melting/freezing characteristics of $\mathrm{Cu} /$ paraffin nanofluid as phase-change material (PCM). Energy \& Fuels. 24(3), 1894-8, 2010.

60. Kashani S, Ranjbar A, Abdollahzadeh M, Sebti S. Solidification of nanoenhanced phase change material (NEPCM) in a wavy cavity. Heat and Mass Transfer. 48(7), 1155-66, 2012.

61. Abdollahzadeh M, Esmaeilpour M. Enhancement of phase change material (PCM) based latent heat storage system with nano fluid and wavy surface. International Journal of Heat and Mass Transfer. 80, 376-85, 2015. 
62. Khodadadi J, Zhang Y. Effects of buoyancy-driven convection on melting within spherical containers. International Journal of Heat and Mass Transfer. 44(8), 1605-18, 2001.

63. Brinkman HC. The Viscosity of Concentrated Suspensions and Solutions. The Journal of Chemical Physics. 20(4), 571, 1952.

64. Maxwell JC, Garnett W, Pesic P. An elementary treatise on electricity: Courier Corporation, 2005.

65. Wakao N, Kagei S. Heat and mass transfer in packed beds. University of Sal ford, UK: Taylor \& Francis, 1982. 
